\title{
Infrared spectra and optical constants of astronomical ices: I. Amorphous and crystalline acetylene
}

\author{
R.L. Hudson ${ }^{\mathrm{a}, *}$, R.F. Ferrante ${ }^{\mathrm{b}}$, M.H. Moore ${ }^{\mathrm{a}}$ \\ ${ }^{a}$ Astrochemistry Laboratory, NASA Goddard Space Flight Center, Greenbelt, MD 20771, United States \\ ${ }^{\mathrm{b}}$ Chemistry Department, U.S. Naval Academy, 572 Holloway Road, Annapolis, MD 21402, United States
}

\section{A R T I C L E I N F O}

\section{Article history:}

Received 10 June 2013

Revised 27 August 2013

Accepted 31 August 2013

Available online 16 October 2013

\section{Keywords:}

Ices, IR spectroscopy

Trans-neptunian objects

Organic chemistry

Infrared observations

\begin{abstract}
A B S T R A C T
Here we report recent measurements on acetylene $\left(\mathrm{C}_{2} \mathrm{H}_{2}\right)$ ices at temperatures applicable to the outer Solar System and the interstellar medium. New near- and mid-infrared data, including optical constants $(n, k)$, absorption coefficients $(\alpha)$, and absolute band strengths $(A)$, are presented for both amorphous and crystalline phases of $\mathrm{C}_{2} \mathrm{H}_{2}$ that exist below $70 \mathrm{~K}$. Comparisons are made to earlier work. Electronic versions of the data are made available, as is a computer routine to use our reported $n$ and $k$ values to simulate the observed IR spectra. Suggestions are given for the use of the data and a comparison to a spectrum of Makemake is made.
\end{abstract}

Published by Elsevier Inc.

\section{Introduction}

The simpler hydrocarbons have long been known, or suspected, to exist in atmospheres and on surfaces in the outer Solar System where they have been studied remotely from Earth and Earth orbit and also by spacecraft instruments. Examples of hydrocarbons reported include frozen methane $\left(\mathrm{CH}_{4}\right)$ on Pluto, ethane $\left(\mathrm{C}_{2} \mathrm{H}_{6}\right)$ in cometary comae, Titan's ethylene $\left(\mathrm{C}_{2} \mathrm{H}_{4}\right)$, and propane $\left(\mathrm{C}_{3} \mathrm{H}_{8}\right)$ in Saturn's atmosphere. In addition to these four hydrocarbon molecules, acetylene $\left(\mathrm{C}_{2} \mathrm{H}_{2}\right)$ also has been observed in the outer Solar System. In cometary comae it is detected with an abundance relative to $\mathrm{H}_{2} \mathrm{O}$ of $0.1-0.5 \%$, and is thought to originate in the ices of cometary nuclei (Mumma et al., 2003). Such ices are believed to be representative of cold interstellar and outer protoplanetary disk regions where comets form. Trace amounts of gas-phase $\mathrm{C}_{2} \mathrm{H}_{2}$ also are found in the hydrogen-rich atmospheres of all of the giant planets, and acetylene has been firmly identified as a major trace gas in the $\mathrm{N}_{2}$-dominated atmosphere of Titan. In fact, Titan's atmospheric $\mathrm{C}_{2} \mathrm{H}_{2}$ may participate in chemical pathways leading to polycyclic aromatic hydrocarbons (PAHs), compounds thought to play a role in the production of Titan's aerosols.

Acetylene's astrochemistry also can include solid forms (ices) of the molecule on the cold surfaces of Pluto and other transneptunian objects (TNOs) where frozen $\mathrm{C}_{2} \mathrm{H}_{2}$ may participate in chemistry driven by cosmic radiation. Laboratory work already has shown that $\mathrm{C}_{2} \mathrm{H}_{2}$ and $\mathrm{C}_{2} \mathrm{H}_{6}$ are radiation products of $\mathrm{CH}_{4}$

\footnotetext{
* Corresponding author. Fax: +1 (301) 2860440.

E-mail address: reggie.hudson@nasa.gov (R.L. Hudson).
}

(Bennett et al., 2006), and so both molecules could be present on outer Solar System icy surfaces with $\mathrm{CH}_{4}$. See Johnson (1989) for details of the radiation environment and time scales for such radiolytic changes. Although the evidence for complex hydrocarbons on Pluto's surface still is limited (Sasaki et al., 2005; Merlin et al., 2010; DeMeo et al., 2010), frozen $\mathrm{CH}_{4}$ has long been known to exist there (Cruikshank et al., 1976). Aside from Pluto, spectral features of $\mathrm{CH}_{4}$ and $\mathrm{C}_{2} \mathrm{H}_{6}$ ices are consistent with observations of Makemake (2005 $\mathrm{FY}_{9}$ ) by Brown et al. (2007) and possibly of Quaoar too (Schaller and Brown, 2007).

Beyond the Solar System, $\mathrm{C}_{2} \mathrm{H}_{2}$ has been identified in the gas phase in molecular hot cores and protostellar environments, where its percent abundance relative to $\mathrm{H}_{2} \mathrm{O}$ is $0.1-0.5$. This abundance cannot be matched by theoretical models without the inclusion of $\mathrm{C}_{2} \mathrm{H}_{2}$ molecules subliming from icy grain mantles (Brown et al., 1988; Nguyen et al., 2002; Stäuber et al., 2005). Carr and Najita (2011) have analyzed rovibrational emission spectra from the Spitzer Space Telescope to determine the gas-phase abundance of $\mathrm{C}_{2} \mathrm{H}_{2}$ in circumstellar matter around $\mathrm{T}$ Tauri stars. See also Willacy and Woods (2009) for acetylene in protostellar disks.

The acetylene molecule possesses a linear geometry with $D_{\infty \mathrm{h}}$ symmetry and so it has no permanent dipole moment and therefore no microwave spectrum. This means that remote sensing studies of extraterrestrial $\mathrm{C}_{2} \mathrm{H}_{2}$ have relied heavily on infrared (IR) observations and lab-based work for their interpretation and quantification (de Bergh et al., 2008). Although IR studies of gasphase $\mathrm{C}_{2} \mathrm{H}_{2}$ have a long history (Levin and Meyer, 1928), laboratory work on $\mathrm{C}_{2} \mathrm{H}_{2}$ ices is far more limited, which in turns hinders searches for solid-phase acetylene on TNOs. In early studies, 
Bottger and Eggers (1964) measured the mid-IR spectra of acetylene at $63 \mathrm{~K}$ and Dows (1966) reported a few measurements of the intensities of three IR features for acetylene ices at $65 \mathrm{~K}$. The first paper to more completely quantify acetylene's IR spectrum apparently was that of Khanna et al. (1988), which presented mid-IR measurements of crystalline $\mathrm{C}_{2} \mathrm{H}_{2}$ at $70 \mathrm{~K}$. Accompanying that work was a table of thirty-one $n$ and $k$ values constituting solid acetylene's optical constants from 3250 to $710 \mathrm{~cm}^{-1}$, and which remain all that are available in print.

Other work on acetylene ices has appeared more recently, but none with direct measurements of band intensities. Boudin et al. (1998) published mid-IR spectra and peak positions for solid $\mathrm{C}_{2} \mathrm{H}_{2}$ near $10 \mathrm{~K}$, both neat and mixed with $\mathrm{H}_{2} \mathrm{O}$ and $\mathrm{CO}$ ices. Infrared band strengths were estimated by comparing acetylene band areas to the areas of IR features whose intensities were known from the work of others. In the near-IR region, publications on $\mathrm{C}_{2} \mathrm{H}_{2}$ ices appear to be limited to a single spectrum covering $7150-4000 \mathrm{~cm}^{-1}$ (Quirico et al., 1999). Most recently, Knez et al. (2012) reported mid-IR spectra of solid $\mathrm{C}_{2} \mathrm{H}_{2}$ and $\mathrm{C}_{2} \mathrm{H}_{2}$ mixed with $\mathrm{H}_{2} \mathrm{O}, \mathrm{CO}, \mathrm{CO}_{2}$, and $\mathrm{CH}_{4}$ ices at multiple temperatures. From that paper, mid-IR spectra of pure amorphous $\mathrm{C}_{2} \mathrm{H}_{2}$ made at $20 \mathrm{~K}$ and then warmed to $80 \mathrm{~K}$ are available electronically. Knez et al. (2012) also measured positions, widths, and strengths for three mid-IR bands.

Motivated by this scarcity of quantitative spectral data on solid $\mathrm{C}_{2} \mathrm{H}_{2}$ and other ices, we recently have initiated a research program to measure optical constants of small molecules relevant to the chemistry of the outer Solar System. In the present paper we present a complete set of spectra and optical constants from roughly 7000 to $500 \mathrm{~cm}^{-1}$ for both the amorphous and crystalline $\mathrm{C}_{2} \mathrm{H}_{2}$ at multiple temperatures. In the next section we describe our experimental procedures for recording IR spectra and measuring the index of refraction of $\mathrm{C}_{2} \mathrm{H}_{2}$ ices as a function of temperature. This is followed by details of our analysis to determine optical constants, band strengths, and absorption coefficients for amorphous and crystalline $\mathrm{C}_{2} \mathrm{H}_{2}$ in the near- and mid-IR regions. Our laboratory results then are presented, followed by optical-constants calculations and some possible applications. Finally, in Section 5 we compare our near-IR spectra of $\mathrm{C}_{2} \mathrm{H}_{2}$ with the spectrum of the dwarf planet Makemake (2005 $\mathrm{FY}_{9}$ ).

\section{Laboratory procedures}

Our experimental setup, ice preparation method, and IR spectral techniques have been described (Moore et al., 2010), and so only a summary is needed here. Briefly, we used a Perkin Elmer Spectrum GX single-beam FTIR spectrometer set up for measurements from 7000 to $500 \mathrm{~cm}^{-1}(1.43-20 \mu \mathrm{m})$. Over this entire range we used a $\mathrm{KBr}$ substrate and vacuum windows on a cryostat capable of cooling to $12 \mathrm{~K}$. The optical constants of the substrate were taken from Li (1976). Spectra were measured at $2-\mathrm{cm}^{-1}$ resolution using a mid-DTGS detector and a $\mathrm{KBr}$ beam splitter, and with 100 scans per spectrum.

The acetylene used in our experiments was Matheson Research Grade, purified by distillation from a liquid nitrogen/ethanol slush bath $(163 \mathrm{~K})$ to remove acetone, used as a stabilizer, and any residual $\mathrm{H}_{2} \mathrm{O}$ and $\mathrm{CO}_{2}$.

\subsection{Ice preparation}

The same procedure was used in the near-IR and mid-IR regions for ice growth and spectral measurements. After cooling the blank $\mathrm{KBr}$ substrate, its spectrum was recorded at 12, 20, 30, 40, 50 60, and $70 \mathrm{~K}$. Gas-phase $\mathrm{C}_{2} \mathrm{H}_{2}$ then was condensed from a vacuum system onto the substrate to form an ice. Amorphous $\mathrm{C}_{2} \mathrm{H}_{2}$ formed when the deposition was carried out at $12 \mathrm{~K}$, and crystalline $\mathrm{C}_{2} \mathrm{H}_{2}$ when the condensation took place at $70 \mathrm{~K}$. The resulting ice's thickness $(h)$ was determined by laser interferometry using Eq. (1)

$h=\frac{N_{\text {fringes }} \lambda}{2 n_{\lambda}}$

where $N_{\text {fringes }}$ was the number of interference fringes observed with a laser of wavelength $\lambda$ passing through an ice of refractive index $n_{\lambda}$ and with the laser beam's path approximately perpendicular to the ice's surface (Groner et al., 1973). In our work, $\lambda=670 \mathrm{~nm}$ and so the corresponding refractive index is denoted $n_{670}$. Ices grown for midIR spectra were limited to about two fringes $(h \approx 0.5 \mu \mathrm{m})$ to prevent the saturation of the stronger bands, whereas ices grown for near-IR spectra typically gave at least twenty fringes $(\sim 5 \mu \mathrm{m})$ so as to ensure good signal-to-noise ratios for the weaker near-IR features. Since we could estimate about $1 / 8$ of a complete fringe, the error in ice thickness was about $6 \%$ for the thinnest ices, dropping to about $0.6 \%$ for the thicker samples. The growth rate of $\mathrm{C}_{2} \mathrm{H}_{2}$ ices was roughly $1 \mu \mathrm{m} \mathrm{h}^{-1}$.

\subsection{Infrared spectral measurements}

Transmission spectra of amorphous ices were recorded from 7000 to $500 \mathrm{~cm}^{-1}(1.43-20 \mu \mathrm{m})$ at $12 \mathrm{~K}$, and then at $20,30,40$, 50,60 , and $70 \mathrm{~K}$ as the sample was warmed. For crystalline ices, an initial spectrum was recorded at $70 \mathrm{~K}$, and then at $60,50,40$, 30,20 , and $15 \mathrm{~K}$ as the sample was cooled. The warming or cooling rate was about $3 \mathrm{~K} \mathrm{~min}^{-1}$. Each ice's single-beam spectrum was ratioed against the background (blank) spectrum of the $\mathrm{KBr}$ substrate recorded at the same temperature, maintained with a precision of $\pm 0.3 \mathrm{~K}$. As discussed by Anderson et al. (1985) and Khanna et al. (1988), the IR and Raman spectra of $\mathrm{C}_{2} \mathrm{H}_{2}$ ice formed at $70 \mathrm{~K}$ are suggestive of an orthorhombic crystalline structure. Although a transition to a cubic crystalline phase occurs at $133 \mathrm{~K}$ (Smith, 1969), it was not studied in our work since $\mathrm{C}_{2} \mathrm{H}_{2}$ ice rapidly sublimes above $80 \mathrm{~K}$ in our vacuum system.

\subsection{Determination of $n_{670}$ for $\mathrm{C}_{2} \mathrm{H}_{2}$ ices}

Values of $n_{670}$ for acetylene ices were needed both for ice-thickness measurements, with Eq. (1), and for the calculation of optical constants (vide infra). Our method for measuring $n_{670}$ of ices has been described (Moore et al., 2010), so again only a summary is given here. We employed a dedicated instrument separate from the set-up used for recording near- and mid-IR spectra for optical constants. Briefly, we condensed $\mathrm{C}_{2} \mathrm{H}_{2}$ at a constant rate onto a cooled $\mathrm{KBr}$ substrate within a vacuum chamber while simultaneously, during the deposition, recording the interference fringes generated from two 670-nm lasers' beams reflected at angles of $\theta_{1}=6.758^{\circ}$ and $\theta_{2}=44.04^{\circ}$ to the substrate. The ratio, $t_{1} / t_{2}$, of the oscillation periods of the two lasers' reflected intensities gave the refractive index through Eq. (2).

$n_{670}=\sqrt{\frac{\sin ^{2} \theta_{2}-\left(t_{1} / t_{2}\right)^{2} \sin ^{2} \theta_{1}}{1-\left(t_{1} / t_{2}\right)^{2}}}$

See, for example, Tempelmeyer and Mills (1968) for a similar use of this same equation. For each ice sample, the maxima and minima of more than ten fringes were measured for each laser so as to reduce the error in determining the periods of oscillation. The constancy of the acetylene's deposition rate was supported by the high correlation coefficients $(>0.99)$ of plots of the time (appearance) for each fringe extrema against each extrema's ordinal number. See also Romanescu et al. (2010) for similar work. A Mattson FTIR spectrometer was interfaced to our two-laser system to verify the amorphous or crystalline nature of each ice. 
The next section shows that to calculate optical constants a reference value, $n_{0}$, for the index of refraction of each acetylene ice was required. Since a slight reduction in $n_{670}$ was expected when extrapolating to longer wavelengths, we took $n_{0}$ to be $0.99 n_{670}$ based on a similar correction by Edwards and Philipp (1985) and our own work (Moore et al., 2010).

\section{Spectral intensities and optical constants}

For some icy solids, the positions, widths, and shapes of spectral features are sufficient for identifying molecules, particularly when coupled with some knowledge of the chemistry of the ice, such as the behavior of similar systems or isoelectronic species. However, the quantitative spectroscopic analysis of ices requires additional information and is usually more difficult to accomplish. At least three approaches to quantifying IR spectral features are in the literature, namely absorption coefficients, band strengths, and optical constants, but seldom are these found in a single study, such as the present one.

Before outlining our work on IR intensities, we point out that spectroscopists have long recognized that optical complexities, both instrumental ones (Wilson and Wells, 1946; Ramsay, 1952) and those inherent to thin samples (Maeda and Schatz, 1961), can complicate band-strength measurements. In what follows, the adjectives "absolute" and "apparent" designate intensities that have and have not been, respectively, corrected for such matters. The use of these adjectives will perhaps seem reasonable to those in astronomical fields, but while these same expressions have been employed by some IR workers (e.g., Wexler, 1967; Scrocco et al., 1972), others have preferred a slightly different terminology (e.g., Thomas and Orville-Thomas, 1971). Similarly, the notation we use for absolute and apparent IR intensities is the same as that of Maeda and Schatz (1961), and resembles that already in the astrochemical literature, but some workers have preferred different symbols (e.g., Avram and Mateescu, 1972; Overend, 1982; Paul and Ford, 1989), and there appears to be no widely-accepted IUPAC convention to cover all such cases.

\subsection{Absorption coefficients and band strengths}

To a first approximation, the intensity of a beam of light before $\left(I_{0}\right)$ and after $(I)$ passing through a sample of thickness $h$ can be described by $I=I_{0} \exp \left(-\alpha^{\prime} h\right)$, the Beer-Lambert law, where $\alpha^{\prime}$ is called the apparent absorption coefficient of the sample. Rearrangement and modification of this equation gives $\log _{10}\left(I_{0} /\right.$ $I)=\alpha^{\prime} h / \ln (10)$, and so it follows that from measurements of both $\log _{10}\left(I_{0} / I\right)$ and $h, \alpha^{\prime}$ can quickly be calculated, such as by taking the slope of a graph of $\log _{10}\left(I_{0} / I\right)$ as a function of thickness $h$. Since $\log _{10}\left(I_{0} / I\right)$ varies with wavenumber, due to the presence of spectral features, an absorption coefficient $\alpha^{\prime}$ is a measure of spectral intensity at a particular wavenumber $\tilde{v}$. However, since IR bands extend over a range of wavenumbers, it is sometimes both necessary and more valuable to discuss spectral intensity in terms of the area under an absorption feature, specifically $\int \alpha^{\prime}(\tilde{v}) d \tilde{v}$, which is the same as $\ln (10) \int \log _{10}\left(I_{0} / I\right) d \tilde{v} / h$. Taking $\rho_{N}$ as the concentration (molecules $\mathrm{cm}^{-3}$ ) of absorbers in a sample then $\int \alpha^{\prime}(\tilde{v}) d \tilde{v}=\rho_{N} A^{\prime}$, where $A^{\prime}$ is a measure of the band's strength on a per molecule basis and usually just termed an apparent " $A$ value", here in units of $\mathrm{cm}$ molecule ${ }^{-1}$. All of these terms can be combined to give Eq. (3)

$A^{\prime}=\frac{\ln (10)}{\rho_{N} h} \int_{\text {band }} \log _{10}\left(\frac{I_{0}}{I}\right) d \tilde{v}$

for determining intensities of IR bands from spectra. The integral itself is simply the area of a spectral band recorded on a common-logarithmic scale. See Hollenberg and Dows (1961) for additional details and examples.

\subsection{Optical constants}

Although $\alpha^{\prime}$ and $A^{\prime}$ are readily found by measuring peak positions and band areas, these measures of spectral intensity include losses due to reflection and interference effects, which can be substantial for thin ice samples (Maeda and Schatz, 1961). In this paper we designate absorption coefficients and band strengths that are free of such complications as $\alpha$ and $A$, respectively. These quantities can be found through a determination of the real and imaginary parts of a sample's complex index of refraction $m \equiv n-i k$ where $n$ and $k$ together are known as optical constants. The quantity $k$ is related to an absorption coefficient by $\alpha=4 \pi \tilde{v} k$. Values of both $n$ and $k$ depend on $\tilde{v}$ and can be used to generate synthetic spectra with which to compare to astronomical observations.

For the present paper we used an iterative process to determine optical constants from high-quality transmission spectra of $\mathrm{C}_{2} \mathrm{H}_{2}$ ices recorded in the near-IR $\left(\sim 7000-3500 \mathrm{~cm}^{-1}\right)$ and mid-IR (4000-500 $\mathrm{cm}^{-1}$ ) regions for amorphous and crystalline samples at multiple temperatures. As already mentioned, the substantial differences in intensities between the fundamental (mid-IR) and higher-wavenumber (near-IR) features required that ices with two different thicknesses, "thin" for mid-IR and "thick" for nearIR, be grown for all amorphous and all crystalline $\mathrm{C}_{2} \mathrm{H}_{2}$ spectral studies. Each single-beam spectrum, $I(\tilde{v})$, of an acetylene ice was divided by a single-beam spectrum, $I_{0}(\tilde{v})$, of the blank $\mathrm{KBr}$ substrate to remove instrumental characteristics before conversion to an absorbance spectrum (i.e., $-\log _{10}\left[I(\tilde{v}) / I_{0}(\tilde{v})\right]$ ). As explained in Moore et al. (2010), the baseline of each such spectrum then was straightened, flattened, and brought to zero, if necessary, then converted back to an $I(\tilde{v}) / I_{0}(\tilde{v})$ ratio, and then multiplied by a theoretical channel-fringe pattern calculated from the thickness and $n_{670}$ of the ice. The result of these manipulations was a starting spectrum $T(\tilde{v})$ for a Kramers-Kronig analysis to obtain infrared $n(\tilde{v})$ and $k(\tilde{v})$ values. This is essentially the procedure that Hudgins et al. (1993, Section 3.2) used to correct for scattering and non-linear baselines.

Our iterative calculations of optical constants began with the lab spectrum $T(\tilde{v})$ just described, from which estimates of $\alpha(\tilde{v})$ for the ice sample were made with

$\alpha(\tilde{v})=-\frac{1}{h} \ln T(\tilde{v})$

followed by the calculation of $k(\tilde{v})$ from

$k(\tilde{v})=\frac{\alpha(\tilde{v})}{4 \pi \tilde{v}}$

and then the first estimate for $n(\tilde{v})$ from Eq. (6), the Kramers-Kronig transformation, using the previously-determined $n_{0}=(0.99) n_{670}$.

$n(\tilde{v})=n_{0}+\left(\frac{2}{\pi}\right) \int \frac{\tilde{v}^{\prime} k\left(\tilde{v}^{\prime}\right)}{\left(\tilde{v}^{\prime}\right)^{2}-(\tilde{v})^{2}} d \tilde{v}^{\prime}$

These $n(\tilde{v})$ values and the original $k(\tilde{v})$ values of (5) were combined to calculate transmission and reflection coefficients (e.g., see Hudgins et al., 1993) to then compute a synthetic spectrum, $I(\tilde{v}) / I_{0}(\tilde{v})$. The latter gave a new set of $\alpha(\tilde{v})$ and, from Eq. (5), a revised set of $k(\tilde{v})$ values, which through Eq. (6) gave a revised set of $n(\tilde{v})$. After each such cycle

spectrum $\rightarrow \alpha(\tilde{v}) \rightarrow k(\tilde{v}) \rightarrow n(\tilde{v}) \rightarrow$ coefficients $\rightarrow$ spectrum

the new transmission spectrum was compared to the original spectrum, $T(\tilde{v})$. The ratio of the calculated and original reference spectra was brought closer to unity by iterating until a self-consistent set of $n(\tilde{v})$ and $k(\tilde{v})$ values was reached and the calculated-to-measured 
ratio of spectra deviated from 1 by less than $10^{-5}$ at all $\tilde{v}$ values. To reach this level of agreement, as many as one hundred iterations were sometimes required for mid-IR spectra, but only twenty for the near-IR data. See Moore et al. (2010) for more on the spectral manipulations and the corresponding calculations, and Keefe et al. (2012) for details and references on the development and application of such methods. All computations were performed with MathCad software and selective independent checking with IDL routines.

Having determined $k(\tilde{v})$, we used Eq. (5) to calculate and plot $\alpha(\tilde{v})$ as a function of $\tilde{v}$ to give a final computed IR spectrum. Integration of the IR bands of this spectrum, and application of Eq. (7), a modification of Eq. (3), then gave us absolute band strengths directly from our optical constants.

$A=\frac{1}{\rho_{N}} \int_{\text {band }} \alpha(\tilde{v}) d \tilde{v}$

Again we note that these absolute band strengths $(A)$ are different from the apparent ones $\left(A^{\prime}\right)$ of Section 3.1.

The largest source of uncertainty in $A$ is the ice's density. We assumed a mass density of $\rho=0.76 \mathrm{~g} \mathrm{~cm}^{-3}$ from work on orthorhomic $\mathrm{C}_{2} \mathrm{H}_{2}$ at $131 \mathrm{~K}$ by McMullan et al. (1992). Data on $\mathrm{C}_{2} \mathrm{H}_{2}$ at lower temperatures is unavailable, but measurements on $\mathrm{C}_{2} \mathrm{D}_{2}$ down to $15 \mathrm{~K}$ by the same research group suggest that the density of $\mathrm{C}_{2} \mathrm{H}_{2}$ will change by less than $10 \%$. The concentration (number density, $\rho_{N}$ ) needed for Eq. (3) is readily found from $\rho$ by $\rho_{N}=\rho N_{A} /$ (MW), where $N_{A}$ is Avogadro's number and MW is the gram molar mass of acetylene $\left(26.04 \mathrm{~g} \mathrm{~mol}^{-1}\right)$. Eq. (7) shows that if new $\rho_{N}$ values become available in the future then they can readily be used to rescale our $A$ values.

\section{Results}

We first present IR spectra of amorphous and crystalline acetylene, then we examine the influence of temperature on the nearand mid-IR absorbances of acetylene, and then we present the results of our $n_{670}$ measurements for $\mathrm{C}_{2} \mathrm{H}_{2}$ ices.

\subsection{Infrared spectra for $\mathrm{C}_{2} \mathrm{H}_{2}$ ices at $7000-500 \mathrm{~cm}^{-1}$}

Fig. $1 \mathrm{a}$ and $\mathrm{b}$ shows the IR spectra of $\mathrm{C}_{2} \mathrm{H}_{2}$ ices at 12 and $15 \mathrm{~K}$ in the near- and mid-IR regions, with peaks and assignments listed in Table 1 . These spectra quickly illustrate the differences in intensity of features in the near- and mid-IR regions. For both solid phases, the strongest band is the $v_{3}$ vibrational mode near $3230 \mathrm{~cm}^{-1}$, which approached saturation for ice thicknesses near $0.5 \mu \mathrm{m}$. Band strengths and absorption coefficients for the $v_{3}$ feature and others are presented later in Section 5.2. We note here that our identifications of the near-IR overtone and combination bands are taken from the gas-phase absorptions close to the positions we observed in the solid phase. More work is required for firmer assignments of these weaker ice features.

Fig. 2 shows spectra of three near-IR and two mid-IR bands on expanded scales. In each case we compare the amorphous ice made at $12 \mathrm{~K}$ with a crystalline ice grown at $70 \mathrm{~K}$ and cooled to $15 \mathrm{~K}$. The near-IR spectra of Fig. 2a, b, e, and $f$ are for ices with a thickness near $5 \mu \mathrm{m}$, while the ices giving the mid-IR spectra of Fig. 2c, d, $\mathrm{g}$, and $\mathrm{h}$ had a thickness near $0.5 \mu \mathrm{m}$. Two spectral properties of amorphous $\mathrm{C}_{2} \mathrm{H}_{2}$ ice are readily illustrated in the mid-IR spectra. First is the symmetric shape of the single-peaked $v_{3}$ band, which has a maximum about $14 \mathrm{~cm}^{-1}$ greater than that of the peak for the crystalline ice. Second, the position of the peak of the strongly asymmetric $v_{5}$ band is about $28 \mathrm{~cm}^{-1}$ less than that of the crystalline ice's double-peaked $v_{5}$ feature. This pronounced asymmetry of an intense band at the smaller wavenumber (longer wavelength) in amorphous $\mathrm{C}_{2} \mathrm{H}_{2}$ is reminiscent of a similar observation by Bertie et al. (1994, 1995).

The spectra of Figs. 1 and 2 were checked with acetylene ices of various thicknesses to ensure that the features shown did not suffer from saturation effects in the regions of interest. That they did not was suggested by the linearity of the associated Beer's Law plots (band area vs. ice thickness). We also recorded spectra at both 2.0 and $0.5 \mathrm{~cm}^{-1}$ resolutions to be sure that these same IR bands were not resolution limited. Only in the case of the sharp $v_{3}$ feature was a difference in area seen, and even then it was only on the order of $3 \%$.

In the early stages of our work two complications arose that should be noted. First, we found that traces of $\mathrm{H}_{2} \mathrm{O}$ vapor in our vacuum systems were manifested by a pair of small IR features of the $\mathrm{H}_{2} \mathrm{O}-\mathrm{C}_{2} \mathrm{H}_{2}$ complex at 3642 and $3565 \mathrm{~cm}^{-1}$ (2.746 and $2.805 \mu \mathrm{m}$ ). In the worse case, these $\mathrm{H}_{2} \mathrm{O}$ molecules amounted to as much as $1 \%$ of the sample, but fortunately this could be reduced to the level of our spectral noise by prolonged pumping on and baking of our vacuum chambers. At the level of such noise, the upper limit to any $\mathrm{H}_{2} \mathrm{O}$ present would have been on the order of $0.001 \%$ of the acetylene sample. Engdahl and Nelander (1983) also detected a $\mathrm{H}_{2} \mathrm{O}-\mathrm{C}_{2} \mathrm{H}_{2}$ complex even in condensed mixtures of $\mathrm{C}_{2} \mathrm{H}_{2}$ diluted and trapped in dry research-grade argon. A second early observation was that when making $\mathrm{C}_{2} \mathrm{H}_{2}$ ices at the lowest temperatures too high a deposition rate gave spectral features that resembled those of our annealed ices. Reproducible IR spectra for amorphous $\mathrm{C}_{2} \mathrm{H}_{2}$, such as those shown as in Figs. 1 and 2, required deposition rates no higher than what were stated in Section 2.1.
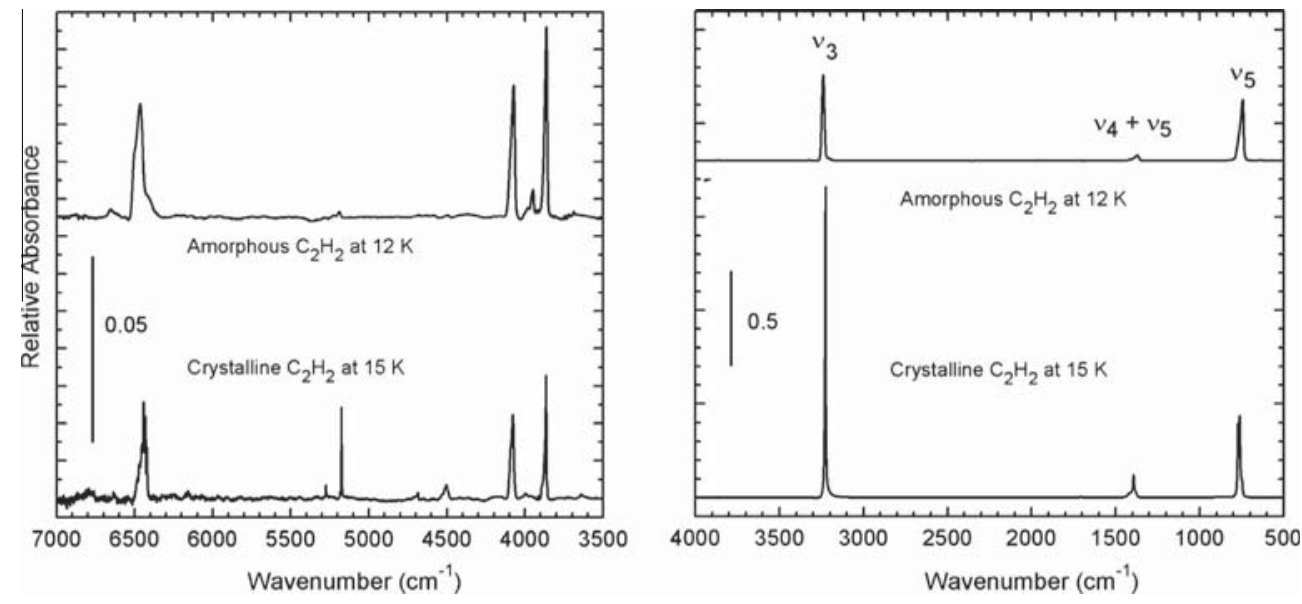

Fig. 1. Near and mid-IR spectra of amorphous and crystalline $\mathrm{C}_{2} \mathrm{H}_{2}$ at 12 and $15 \mathrm{~K}$, respectively. 
Table 1

Peak positions of IR absorptions of solid $\mathrm{C}_{2} \mathrm{H}_{2}$.

\begin{tabular}{|c|c|c|}
\hline $\begin{array}{l}\text { Amorphous, } 12 \mathrm{~K} \\
\tilde{v}\left(\mathrm{~cm}^{-1}\right)\end{array}$ & $\begin{array}{l}\text { Crystalline } 15 \mathrm{~K} \\
\tilde{v}\left(\mathrm{~cm}^{-1}\right)\end{array}$ & Vibrational mode ${ }^{a}$ \\
\hline 6465 & $6485,6482,6472,6466,6454,6452,6442,6431,6421$ & $v_{1}+v_{3}\left(v_{2}+v_{3}+2 v_{4} ?\right)$ \\
\hline- & $5275 \mathrm{w}$ & $v_{1}+2 v_{4}+v_{5}$ \\
\hline 5189 w & 5183 sh, 5174 & $5 v_{4}+3 v_{5}$ \\
\hline- & $4684 \mathrm{w}$ & $v_{1}+v_{4}+v_{5}$ \\
\hline- & $4502 \mathrm{w}$ & $v_{3}+2 v_{4}$ \\
\hline 4072 & 4077 & $v_{1}+v_{5}$ \\
\hline 3948 & - & $2 v_{2}$ \\
\hline 3862 & 3864 & $v_{2}+2 v_{4}+v_{5}$ \\
\hline- & $3438,3428,3393 \mathrm{sh}$ & $v_{2}+2 v_{5}$ \\
\hline 3328 & $3349 \mathrm{sh}, 3333,3318 \mathrm{sh}$ & $v_{1}$ \\
\hline- & $3306,3296 \mathrm{sh}$ & - \\
\hline- & 3279 & - \\
\hline 3240 & 3226 & $v_{3}$ \\
\hline 1419 sh, 1371 & $1419 \mathrm{sh}, 1393,1374 \mathrm{sh}$ & $v_{4}+v_{5}$ \\
\hline 742 & $792 \mathrm{sh}, 770,761,745 \mathrm{sh}$ & $v_{5}$ \\
\hline 634 & - & $v_{4}$ \\
\hline
\end{tabular}

a Assignments are based largely on gas-phase data in the GEISA 2011 spectroscopic database (http://ether.ipsl.jussieu.fr/etherTypo/?id=1293\&L=0, Laboratoire de Mété-

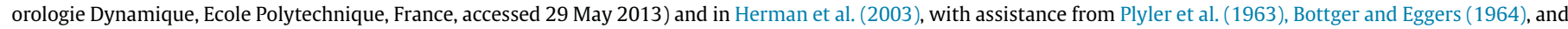
Anderson et al. (1985). Some assignments, particularly those for $\tilde{v}>4000 \mathrm{~cm}^{-1}$, should be regarded as tentative.
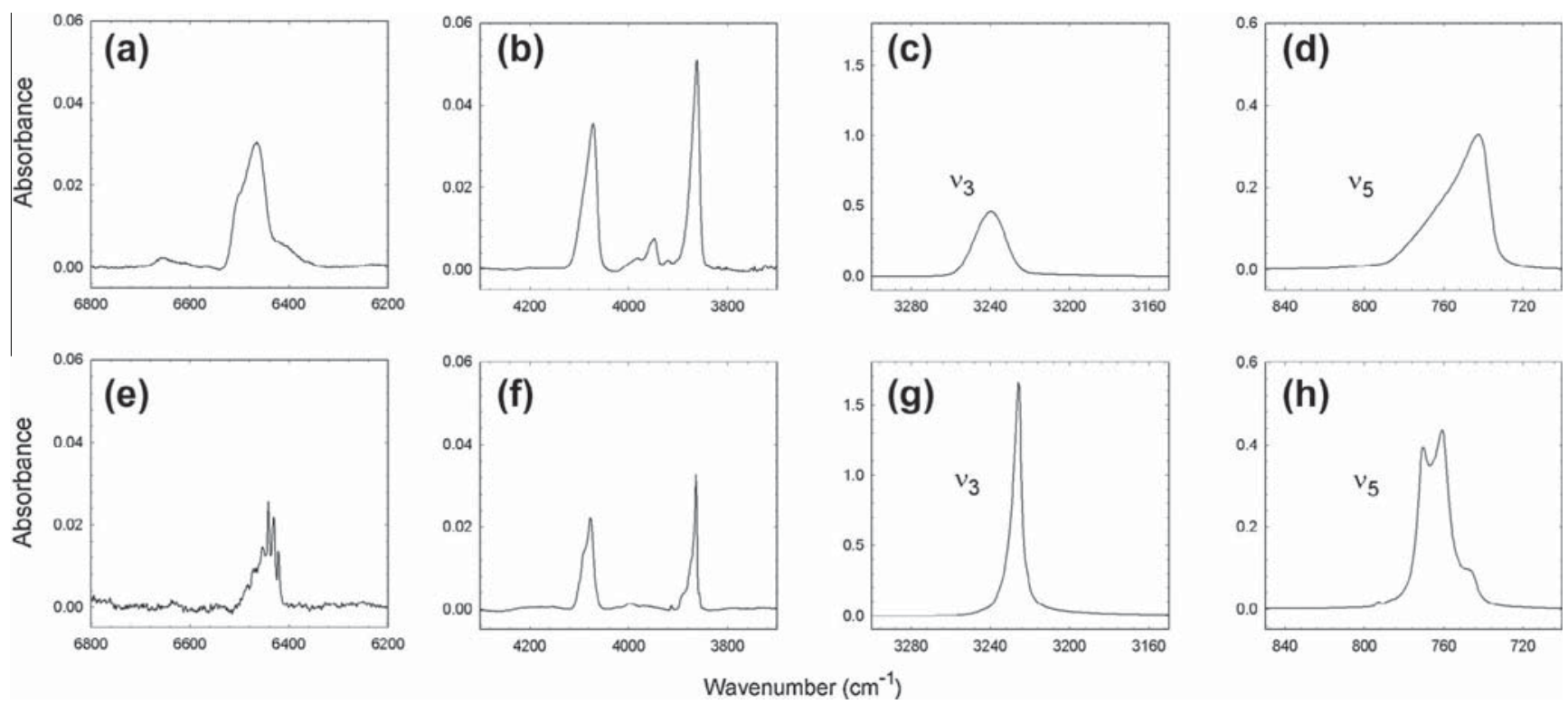

Fig. 2. Details of several major IR features of amorphous (a-d) and crystalline (e-h) $\mathrm{C}_{2} \mathrm{H}_{2}$ at 12 and $15 \mathrm{~K}$, respectively.

\subsection{Infrared spectra of $\mathrm{C}_{2} \mathrm{H}_{2}$ ices as a function of temperature}

The near- and mid-IR spectra of $\mathrm{C}_{2} \mathrm{H}_{2}$ ice on warming from $12 \mathrm{~K}$ are shown in Fig. 3. Between 40 and $50 \mathrm{~K}$ irreversible changes in band shapes and positions, particularly in the 6500, 3300, and $750 \mathrm{~cm}^{-1}$ regions, suggest that the amorphous ice converted into a more crystalline form. Fig. 4 is an enlargement of the $3300 \mathrm{~cm}^{-1}\left(v_{3}\right)$ feature clearly showing the change in the spectra of amorphous $\mathrm{C}_{2} \mathrm{H}_{2}$ on warming from 40 to $50 \mathrm{~K}$. However, the spectra of such warmed amorphous $\mathrm{C}_{2} \mathrm{H}_{2}$ ices never matched the spectra of crystalline $\mathrm{C}_{2} \mathrm{H}_{2}$ ices grown at $70 \mathrm{~K}$, and this is illustrated in more detail in Figs. 5 and 6. The three panels of Fig. 5 show the $v_{5}$ band of $\mathrm{C}_{2} \mathrm{H}_{2}$ ice made under different conditions. Fig. 5a shows IR spectra of amorphous $\mathrm{C}_{2} \mathrm{H}_{2}$ made at $12 \mathrm{~K}$ and warmed to $70 \mathrm{~K}$. At $12 \mathrm{~K}$ the peak of the $v_{5}$ band is at $742 \mathrm{~cm}^{-1}$, but on warming it broadens and develops several components with a maximum at $758 \mathrm{~cm}^{-1}$ at $70 \mathrm{~K}$. Fig. $5 \mathrm{~b}$ shows the spectrum of crystalline $\mathrm{C}_{2} \mathrm{H}_{2}$ formed at $70 \mathrm{~K}$ and then cooled. The spectrum of the $70 \mathrm{~K}$ ice has a double-peaked shape with maxima at 769 and $761 \mathrm{~cm}^{-1}$. Only minor changes in intensity, shape, and position are seen on cooling the sample. Fig. 5c compares spectra of ices grown and measured at temperatures from 12 to $70 \mathrm{~K}$, showing that each possesses a unique shape in the $20-40 \mathrm{~K}$ region.

The contrast between the shapes and positions of the $v_{5}$ feature at $20 \mathrm{~K}$ using three different formation conditions is shown in Fig. 6. Spectrum (a) is for an ice grown at $12 \mathrm{~K}$ and warmed to $20 \mathrm{~K}$, spectrum (b) is for one grown at $12 \mathrm{~K}$ and warmed at $70 \mathrm{~K}$ before recooling to $20 \mathrm{~K}$, and spectrum (c) is for an acetylene ice that was grown at $70 \mathrm{~K}$ and then cooled to $20 \mathrm{~K}$. The differences in (a), (b), and (c) are obvious. For acetylene we found from the $v_{5}$ feature in Fig. 6, and from every major band at $7000-500 \mathrm{~cm}^{-1}$, that we were unable to form a purely-crystalline phase simply by annealing an amorphous ice. We suspect that in each attempt a fraction of amorphous material remained. The purely-crystalline phase 

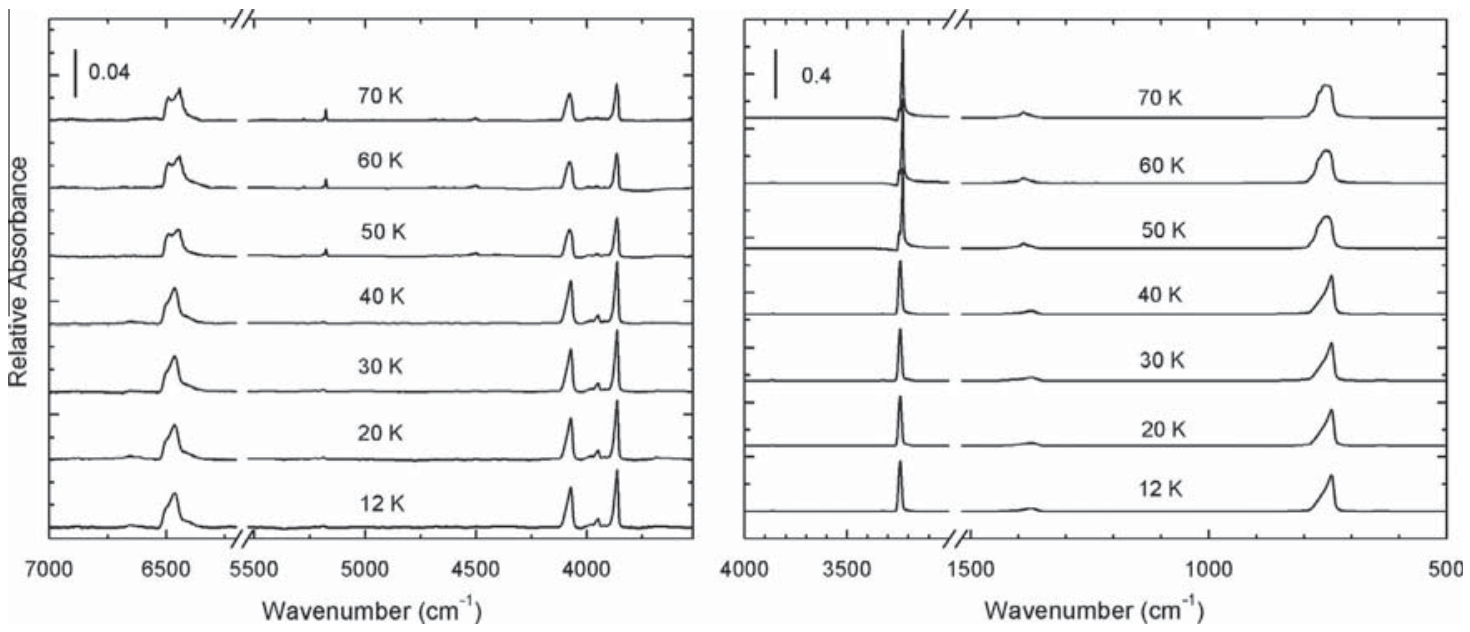

Fig. 3. Near- and mid-IR spectra of amorphous $\mathrm{C}_{2} \mathrm{H}_{2}$ from 12 to $70 \mathrm{~K}$.

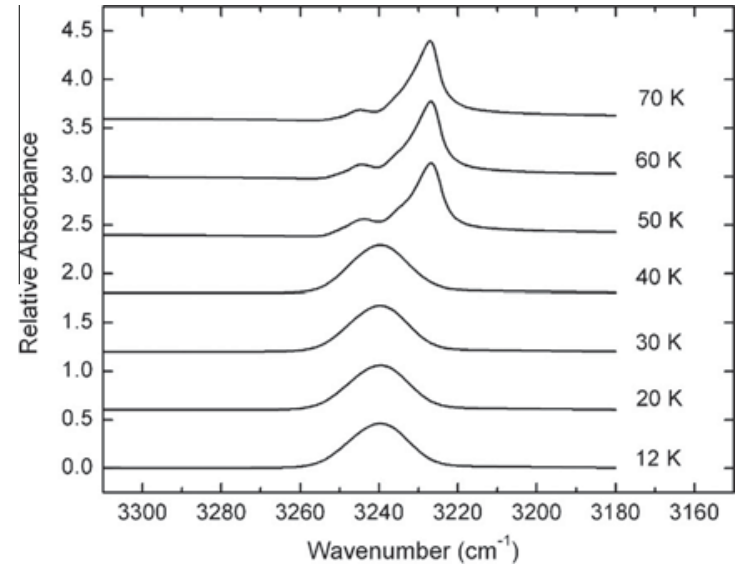

Fig. 4. The $v_{3} \mathrm{C}_{2} \mathrm{H}_{2}$ absorption for amorphous $\mathrm{C}_{2} \mathrm{H}_{2}$ formed at $12 \mathrm{~K}$ and warmed to $70 \mathrm{~K}$.

required a higher formation temperature (i.e., $70 \mathrm{~K}$ ) of the ice, which is why we chose to make depositions at $70 \mathrm{~K}$ to generate crystalline acetylene.

\subsection{Refractive indices for $\mathrm{C}_{2} \mathrm{H}_{2}$ ices at $670 \mathrm{~nm}$}

Fig. 7 shows the values we measured for $n_{670}$ for $\mathrm{C}_{2} \mathrm{H}_{2}$ ices grown at $11-70 \mathrm{~K}$, with each point being the average of at least three measurements. Using a standard method for the propagation of errors (Taylor, 1997; Garland et al., 2003), we estimated the uncertainties of these values to be about \pm 0.015 , which is $\sim 1 \%$ of $n_{670}$.

The most-striking thing about Fig. 7 is undoubtedly the dip at $20-40 \mathrm{~K}$. Infrared spectra of the ices used for our $n_{670}$ measurements were recorded, and they had the same features already described, namely those in Fig. $5 \mathrm{c}$ in which $\mathrm{C}_{2} \mathrm{H}_{2}$ was deposited at a similar set of temperatures. In other words, the fall and rise in $n_{670}$ on going from 20 to $40 \mathrm{~K}$ in Fig. 7 was correlated with the temperature-dependent spectral changes in Fig. $5 c$, where unique annealed forms of the acetylene ice were formed on making the amorphous material. At present we have no firm explanation for this behavior in $n_{670}$, although it is possible to invoke the formation of inhomogeneous regions or even voids in the ice on formation. Other ices examined (e.g., $\mathrm{N}_{2}, \mathrm{CO}_{2}$ ) did not show this same behavior.
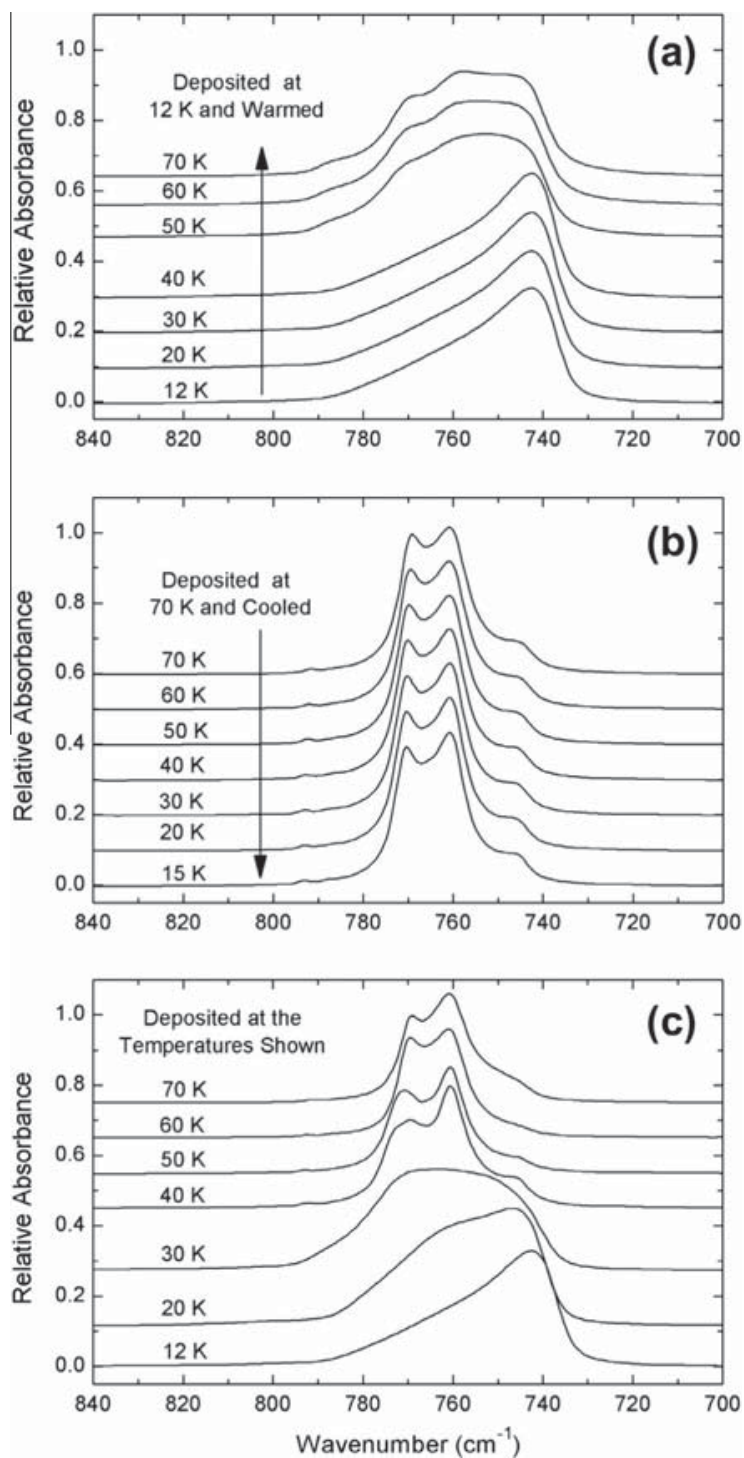

Fig. 5. The band shape and position of the $v_{5} \mathrm{C}_{2} \mathrm{H}_{2}$ absorption for different formation conditions: (a) amorphous $\mathrm{C}_{2} \mathrm{H}_{2}$ formed at $12 \mathrm{~K}$ and warmed to $70 \mathrm{~K}$, (b) crystalline $\mathrm{C}_{2} \mathrm{H}_{2}$ formed at $70 \mathrm{~K}$ and cooled to $12 \mathrm{~K}$, and (c) $\mathrm{C}_{2} \mathrm{H}_{2}$ ice formed at different temperatures from 12 to $70 \mathrm{~K}$. The thickness of each ice was about $0.5 \mu \mathrm{m}$. 


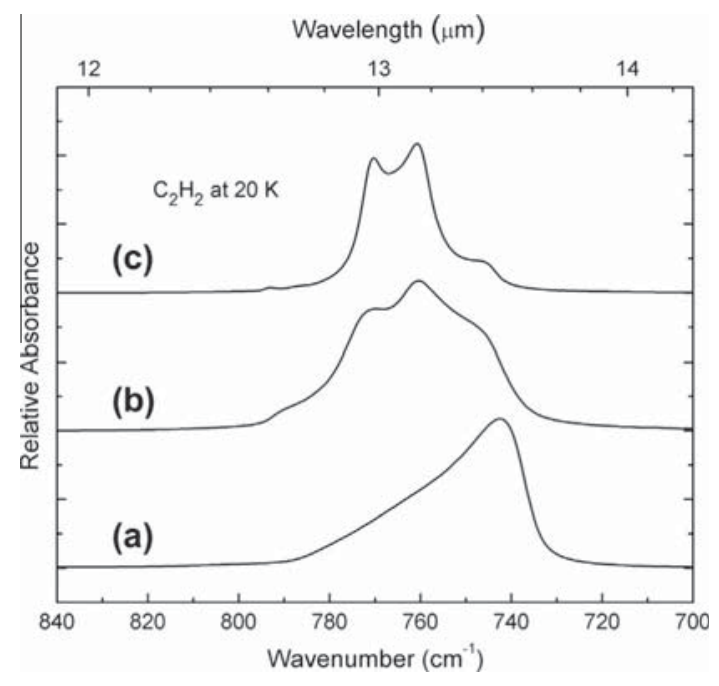

Fig. 6. Different formation conditions result in different $v_{5}$ band shapes for $\mathrm{C}_{2} \mathrm{H}_{2}$ ice: (a) amorphous $\mathrm{C}_{2} \mathrm{H}_{2}$ at $15 \mathrm{~K}$, (b) amorphous $\mathrm{C}_{2} \mathrm{H}_{2}$ warmed to $70 \mathrm{~K}$ and then returned to $15 \mathrm{~K}$, and (c) crystalline $\mathrm{C}_{2} \mathrm{H}_{2}$ cooled to $15 \mathrm{~K}$.

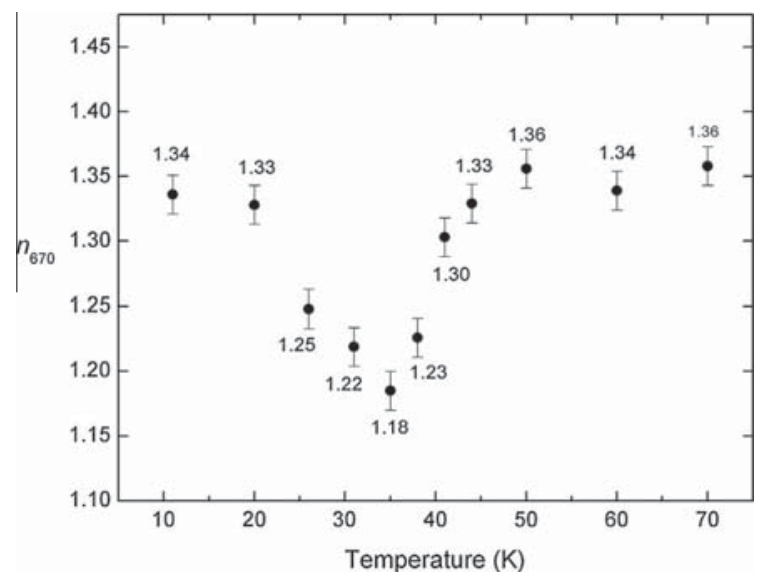

Fig. 7. Index of refraction of solid $\mathrm{C}_{2} \mathrm{H}_{2}$ at $670 \mathrm{~nm}$ as a function of the ice's growth temperature.

In our calculations of ice thicknesses and in our optical constants work we were concerned only with ices grown at temperatures on the opposite ends of Fig. 7, highly amorphous $\mathrm{C}_{2} \mathrm{H}_{2}$ formed at $12 \mathrm{~K}$ and highly crystalline $\mathrm{C}_{2} \mathrm{H}_{2}$ made at $70 \mathrm{~K}$. For this reason we used only $n_{670}=1.33$ and 1.36 in all calculations, the choice depending on whether the sample was deposited at 12 or $70 \mathrm{~K}$, respectively. Our own estimates showed that varying the initial value of $n_{670}$ in a Kramers-Kronig analysis by $10 \%$ could lead to absolute errors in the final values of $\alpha$ and $A$ of up to $10 \%$, but the precise direction and amount of variation were difficult to predict.

\section{Discussion}

\subsection{IR spectra of $\mathrm{C}_{2} \mathrm{H}_{2}$ ices at $7000-500 \mathrm{~cm}^{-1}$}

Our spectra of crystalline $\mathrm{C}_{2} \mathrm{H}_{2}$ ices in Figs 1-6 are essentially the same as those published by others (Bottger and Eggers, 1964; Khanna et al., 1988), although our work has the advantage of covering wider ranges of temperature and wavenumber. For amorphous $\mathrm{C}_{2} \mathrm{H}_{2}$, the only published mid-IR spectrum of which we are aware is that of Boudin et al. (1998). Fig. 8 compares spectra of our (a) amorphous and (b) crystalline ices with a spectrum of Boudin et al. (1998) said to be for a sample of acetylene deposited at $10 \mathrm{~K}$. The close resemblance of traces (b) and (c) in Fig. 8 suggests that it is likely that the ices of Boudin et al. (1998) were annealed, perhaps unintentionally, or that their $\mathrm{C}_{2} \mathrm{H}_{2}$ deposition rate was high enough to have warmed or even partially crystallized their sample. This conclusion is supported by an inspection of the relative intensities and positions of their $v_{3}$ and $v_{5}$ absorbances compared to what we show in this paper.

\subsection{Optical constants and band strengths of $\mathrm{C}_{2} \mathrm{H}_{2}$ ices at 7000-500} $\mathrm{cm}^{-1}$

The IR spectra and other data presented in Section 4 allowed us to calculate optical constants of our acetylene ices. Figs. 9 and 10 show $n(\tilde{v})$ and $k(\tilde{v})$ at seven temperatures for amorphous and crystalline $\mathrm{C}_{2} \mathrm{H}_{2}$. Near- and mid-IR transmission spectra also are shown for each phase, and are included to illustrate the relative intensities of the molecule's absorptions. These are our spectra that have been baseline corrected, using the steps outlined in Section 3, to give a maximum transmission of 1.00 over the range shown. For the amorphous ice, the sample for near-IR measurements had a thickness of $6.5 \mu \mathrm{m}$, while the sample for mid-IR spectra had a thickness of $0.50 \mu \mathrm{m}$. A value of $n_{670}=1.33$ was used for determining these thicknesses and in the subsequent Kramers-Kronig analysis at each temperature. For the crystalline ice, the sample for near-IR measurements had a thickness of $4.6 \mu \mathrm{m}$, while the sample for mid-IR spectra had a thickness of $0.49 \mu \mathrm{m}$. A value of $n_{670}=1.36$ was used for determining these thicknesses and in the subsequent Kramers-Kronig analysis at each temperature of the crystalline material. Calculations were done at one point per $0.5 \mathrm{~cm}^{-1}$.

Table 2 summarizes some key results from our spectra and calculations, listing peak positions, absorption coefficients $(\alpha)$, and band strengths $(A)$ for $\mathrm{C}_{2} \mathrm{H}_{2}$ ices near $12 \mathrm{~K}$. An analysis of such values from 12 to $70 \mathrm{~K}$ showed that neither $\alpha$ nor $A$ possessed a strong temperature dependence ( $<10 \%$ change) for either the amorphous or crystalline phases of $\mathrm{C}_{2} \mathrm{H}_{2}$ ice. For example, cooling from 70 to $15 \mathrm{~K}$ gave little change in $A$ for the $v_{5}$ band of Fig. $5 \mathrm{~b}$, and neither did warming an amorphous sample from 12 to $40 \mathrm{~K}$, as in Fig. $5 \mathrm{a}$. However, on warming an amorphous sample through the 40-to$50 \mathrm{~K}$ region $A\left(v_{5}\right)$ increased by about $22 \%$ when the sample crystallized. In short, the $\alpha$ and $A$ numbers of Table 2 can be used for a first approximation of $\alpha$ and $A$ at other temperatures provided that there is no phase difference involved.

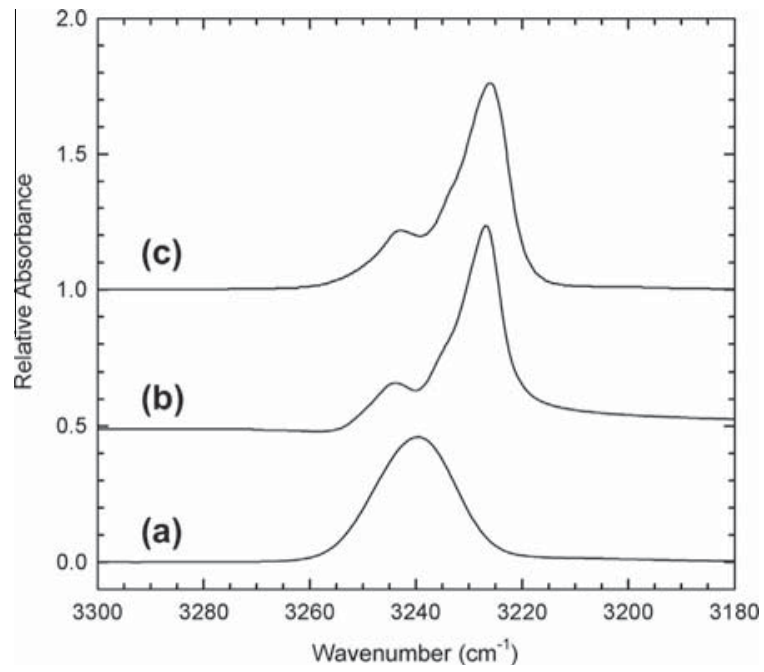

Fig. 8. Spectra of (a) amorphous and (b) crystalline $\mathrm{C}_{2} \mathrm{H}_{2}$ at $\sim 12 \mathrm{~K}$ from this work compared to (c) a spectrum of $\mathrm{C}_{2} \mathrm{H}_{2}$ reported to be deposited and measured near $10 \mathrm{~K}$ (Boudin et al., 1998). 

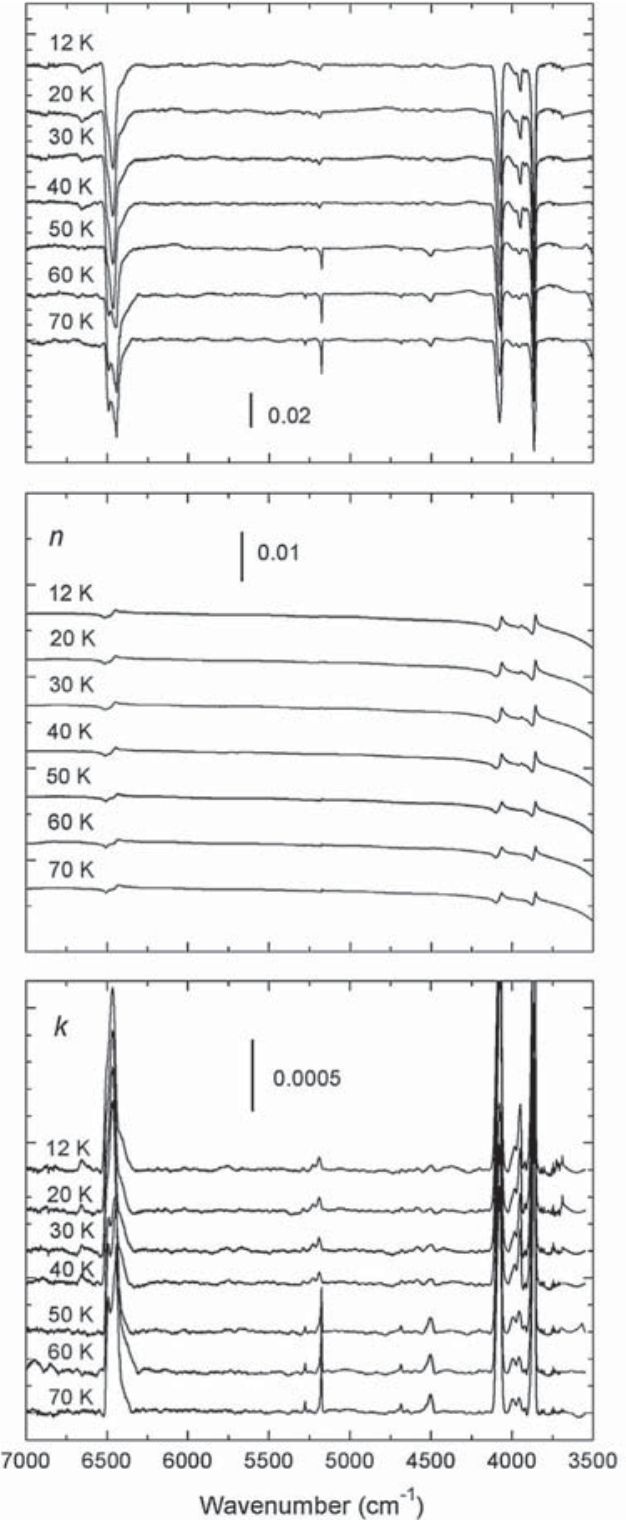
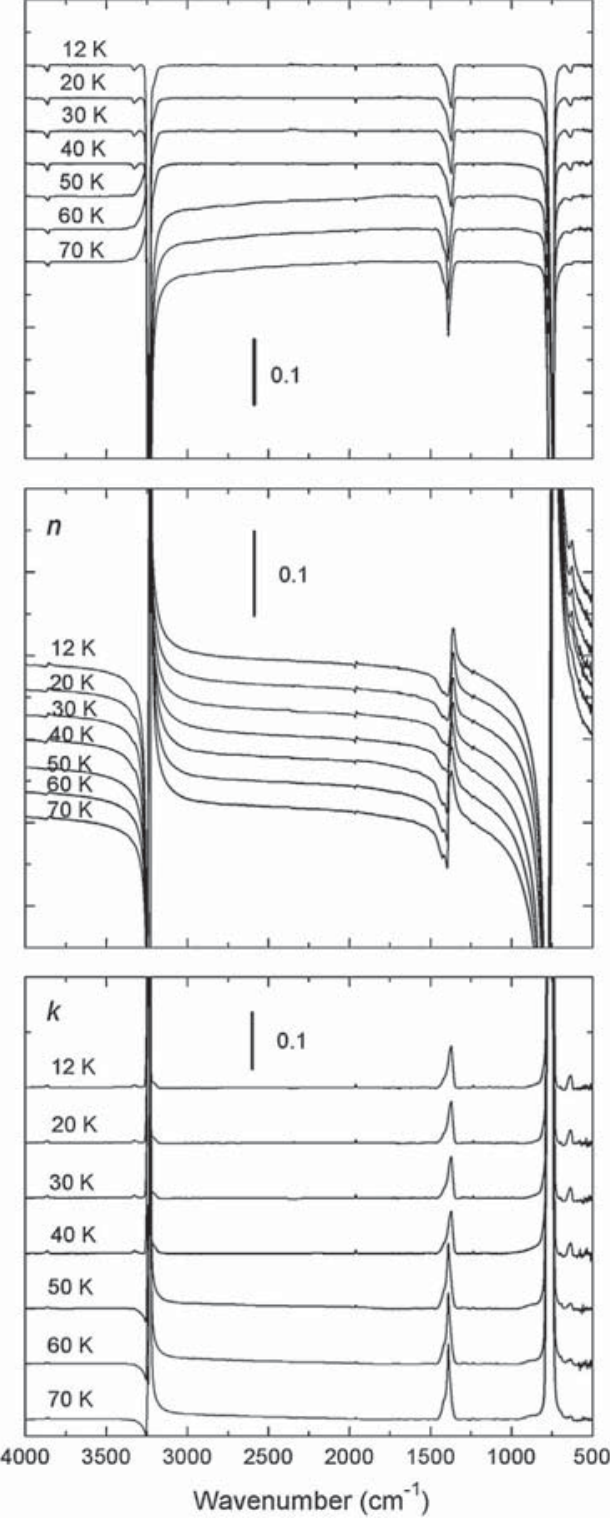

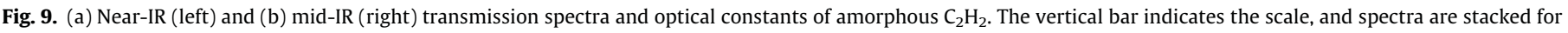
clarity. The samples giving the near- and mid-IR features shown had thicknesses of 6.5 and $0.50 \mu \mathrm{m}$, respectively.

Another comparison we made was between $A$ and $A^{\prime}$, the absolute band strengths determining by integrating $k$ values and the apparent band strengths calculated by integrating the laboratory spectra. Table 3 compares our values of $A$ and $A^{\prime}$ for amorphous acetylene, and shows that the differences are small. As already stated, we know of no comparable results for amorphous $\mathrm{C}_{2} \mathrm{H}_{2}$ in the literature, but for crystalline $\mathrm{C}_{2} \mathrm{H}_{2}$ Table 4 lists our $A$ and $A^{\prime}$ values alongside those from two other groups. Our results are in reasonable agreement with the work of Khanna et al. (1988), but little more can be said since the temperatures they used to make their ices are unknown, as is the nature of the annealing treatment they used. Dows (1966) did not explicitly state either the spectral resolution of his measurement, his sample's thickness, or the substrate material. His $A^{\prime}\left(v_{3}\right)$ is nearly twice the size of ours, and Khanna's, but other values are comparable. Beyond these general statements, little can be said in a quantitative way. Checks for possible saturation effects and resolution limitations were not mentioned in either of the previous papers, although we presume that such checks were made.
An important test of our optical constants is their ability to predict spectral variations among ices of different thicknesses, as opposed to just those particular thicknesses used for our Figs. 1-6. In most cases such differences were small, and amounted to the usual increases in intensity with thickness. These were easily replicated with the usual $I=I_{0} \exp (-4 \pi \tilde{v} k h)$ Beer's Law relation using our computed $k(\tilde{v})$ values. However, the $v_{5}$ feature of crystalline acetylene proved to be a more-severe challenge. Fig. 11a compares spectra of crystalline $\mathrm{C}_{2} \mathrm{H}_{2}$ ices calculated with our $k(\tilde{v})$ values and Beer's Law at six thicknesses. The changes shown are as expected, but these spectra do not match the laboratory data. In contrast, Fig. 11b shows IR spectra calculated with equation A1 of Swanepoel (1983), which uses both $n(\tilde{v})$ and $k(\tilde{v})$ to account for the optical interference and reflection effects present. Significant changes in the band's shape and the peaks' positions are obvious on going from 0.25 to $2.00 \mu \mathrm{m}$. We emphasize that it is the calculated spectra of Fig. 11b that match our laboratory spectra to within $10^{-5}$, as mentioned earlier. Only when both $n(\tilde{v})$ and $k(\tilde{v})$ were used to correct for optical interference and reflection effects was 

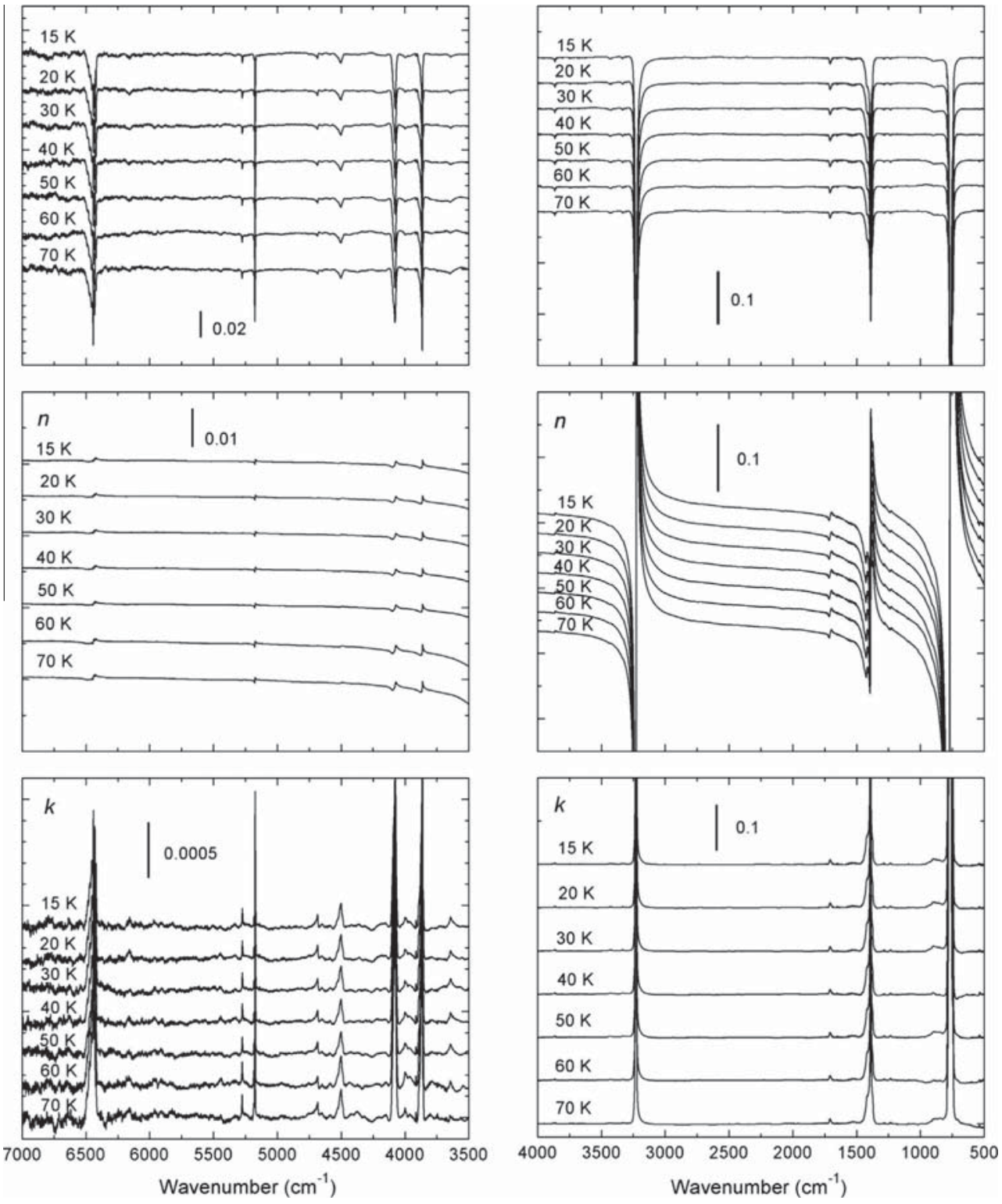

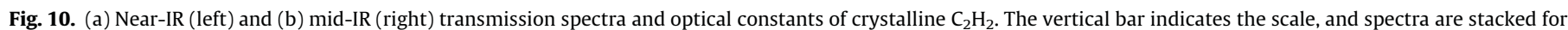
clarity. The samples giving the near- and mid-IR features shown had thicknesses of 4.6 and $0.49 \mu \mathrm{m}$, respectively.

Table 2

Positions, absorption coefficients $(\alpha)$, and band strengths $(A)$ for selected $\mathrm{C}_{2} \mathrm{H}_{2}$ features.

\begin{tabular}{|c|c|c|c|c|c|c|c|c|}
\hline \multirow[t]{2}{*}{ Vibrational mode ${ }^{a}$} & \multicolumn{4}{|c|}{ Amorphous $\mathrm{C}_{2} \mathrm{H}_{2}$ at $12 \mathrm{~K}$} & \multicolumn{4}{|c|}{ Crystalline $\mathrm{C}_{2} \mathrm{H}_{2}$ at $15 \mathrm{~K}$} \\
\hline & $\tilde{\tilde{v}}\left(\mathrm{~cm}^{-1}\right)$ & $\lambda(\mu \mathrm{m})$ & $\alpha\left(\mathrm{cm}^{-1}\right)$ & $A\left(10^{-18} \mathrm{~cm}\right.$ molecule $\left.{ }^{-1}\right)$ & $\overline{\tilde{v}}\left(\mathrm{~cm}^{-1}\right)$ & $\lambda(\mu \mathrm{m})$ & $\alpha\left(\mathrm{cm}^{-1}\right)$ & $A\left(10^{-18} \mathrm{~cm}\right.$ molecule $\left.{ }^{-1}\right)$ \\
\hline$v_{1}+v_{3}$ & 6465 & 1.523 & 110 & 0.42 & 6442 & 1.552 & 87 & 0.16 \\
\hline $5 v_{4}+3 v_{5}$ & - & - & - & - & 5174 & 1.933 & 82 & 0.02 \\
\hline$v_{1}+v_{5}$ & 4072 & 2.456 & 129 & 0.23 & 4077 & 2.453 & 77 & 0.11 \\
\hline$v_{2}+2 v_{4}+v_{5}$ & 3862 & 2.589 & 175 & 0.21 & 3864 & 2.588 & 115 & 0.08 \\
\hline$v_{2}+2 v_{5}$ & - & - & - & - & 3428 & 2.917 & 54 & 0.11 \\
\hline$v_{1}$ & 3328 & 3.005 & 183 & 0.59 & 3333 & 3.000 & 57 & 0.06 \\
\hline$v_{3}$ & 3240 & 3.086 & 22,470 & 23.9 & 3226 & 3.100 & 78,240 & 35.0 \\
\hline$v_{4}+v_{5}$ & 1371 & 7.294 & 1296 & 3.1 & 1393 & 7.179 & 5675 & 6.7 \\
\hline \multirow[t]{2}{*}{$v_{5}$} & 742 & 13.48 & 11,740 & 24.2 & 770 & 12.98 & 19,460 & 22.2 \\
\hline & & & & & 761 & 13.14 & 14,780 & \\
\hline
\end{tabular}

a See the footnote of Table 1 for comments on spectral assignments.

agreement reached between the lab and the calculated results. Put another way, Fig. 11a corresponds to a calculation of an absorbance spectrum free of interference and reflection effects, while Fig. 11b corresponds to an absorbance spectrum where such complications are present, just as they are in a laboratory ice sample. 
Table 3

Band strengths for amorphous $\mathrm{C}_{2} \mathrm{H}_{2}$ at $12 \mathrm{~K}\left(10^{-18} \mathrm{~cm}\right.$ molecule $\left.{ }^{-1}\right)$.

\begin{tabular}{lrr}
\hline Vibrational mode & \multicolumn{1}{c}{$A$} & \multicolumn{1}{c}{$A^{\prime}$} \\
\hline$v_{3}$ & 23.9 & 23.7 \\
$v_{4}+v_{5}$ & 3.1 & 3.4 \\
$v_{5}$ & 24.2 & 27.5 \\
\hline
\end{tabular}

Table 4

Band strengths for crystalline $\mathrm{C}_{2} \mathrm{H}_{2}$ at $\sim 70 \mathrm{~K}\left(10^{-18} \mathrm{~cm}\right.$ molecule $\left.\mathrm{e}^{-1}\right)$.

\begin{tabular}{llllll}
\hline $\begin{array}{l}\text { Vibrational } \\
\text { mode }\end{array}$ & $\begin{array}{l}\text { A, Khanna } \\
\text { et al. (1988) }\end{array}$ & $\begin{array}{l}\text { A, this } \\
\text { work }\end{array}$ & $\begin{array}{l}A^{\prime} \text {, this } \\
\text { work }\end{array}$ & $\begin{array}{l}A^{\prime} \text {, Khanna } \\
\text { et al. (1988) }\end{array}$ & $\begin{array}{l}A^{\prime} \text {, Dows } \\
(1966)\end{array}$ \\
\hline$v_{3}$ & 21.3 & 35.8 & 37.0 & 35.7 & 65.2 \\
$v_{4}+v_{5}$ & 5.98 & 6.2 & 7.6 & 6.1 & 8.47 \\
$v_{5}$ & 13.8 & 22.3 & 26.9 & 19.1 & 18.3 \\
\hline
\end{tabular}
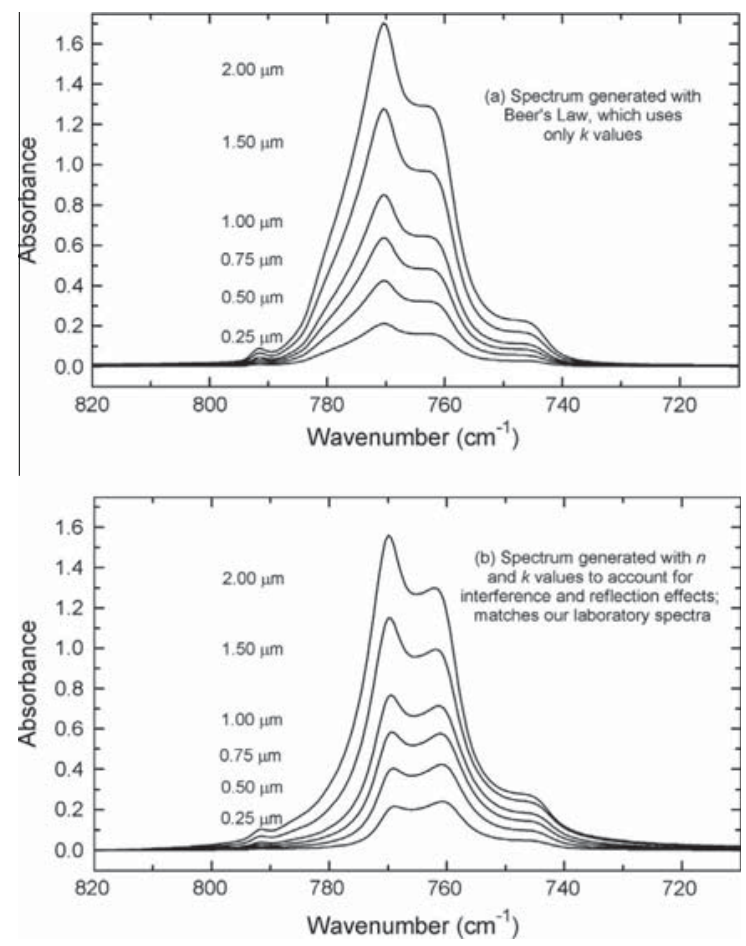

Fig. 11. Simulations of IR spectra of crystalline $\mathrm{C}_{2} \mathrm{H}_{2}$ at $70 \mathrm{~K}$ as a function of thickness as calculated with (a) Beer's Law, which uses only $n(\tilde{v})$ values, and (b) $n(\tilde{v})$ and $k(\tilde{v})$ values to reproduce the interference and reflection effects in a real sample. Numbers in $\mu \mathrm{m}$ units refer to the ice's thickness.

Finally, we note that although the calculation of IR spectra from $n(\tilde{v})$ and $k(\tilde{v})$ values has long been studied, it is difficult to locate simple computer routines with sufficient detail and documentation for the necessary computations. We have found that the work of Swanepoel (1983) provides a particularly convenient approach to calculating spectra from $n(\tilde{v})$ and $k(\tilde{v})$, and that while it has been heavily used by engineers and materials scientists, it seldom has been cited by workers within the astrochemical community. A version of Swanepoel's equations, adapted for Microsoft Excel (or equivalent) software, is posted on our web pages ${ }^{1}$ for the use of all interested parties. Our $n(\tilde{v})$ and $k(\tilde{v})$ results, and those of others, can be used with this program to rapidly generate synthetic spectra without the need for more-expensive software.

\footnotetext{
1 http://science.gsfc.nasa.gov/691/cosmicice/constants.html.
}

\subsection{Some comments on errors}

The input for each of our optical-constants calculations consisted of a high-quality IR transmission spectrum, a reference index of refraction $\left(n_{0}\right)$, and the sample's thickness $(h)$. The good reproducibility of our results when data sets were combined from independent investigators working with different equipment over more than a year in two different laboratories gave us confidence that our IR spectra were of high quality and not a significant source of error. Our $n_{0}$ measurements resulted in small errors $(\sim 1 \%)$, and these can produce a vertical shift of the calculated infrared $n$ values by the same amount, as suggested by Eq. (6). The thickness $h$ of each ice sample could be measured with confidence to within about an eighth of an interference fringe, which corresponds to around $0.03 \mu \mathrm{m}$ in thickness or about $6 \%$ of the thickness of the smallest samples $(\sim 0.5 \mu \mathrm{m})$. We believe that this is the dominant source of error in all of our results, as it is with those of Hudgins et al. (1993). To further check our error analysis, we also calculated optical constants starting with values of $h$ and $n_{0}$ known to be incorrect by $\sim 10 \%$, and we then analyzed the resulting $k$ values to determine band strengths $(A)$ and absorption coefficients $(\alpha)$. In no cases were the resulting $A$ and $\alpha$ of Tables 2-4 changed by as much as $10 \%$ even for acetylene's strongest IR features in Table 2 . Additional insight into uncertainties might be possible through a full propagation-of-errors analysis of the iterative Kramers-Kronig method that we used. So far as we are aware, no such analysis has appeared in the literature, despite the method's long and widespread use.

\subsection{Applications}

The spectral properties of $\mathrm{C}_{2} \mathrm{H}_{2}$ between 7000 and $500 \mathrm{~cm}^{-1}$ are of interest for comparison with both near-IR observations of cold icy surfaces, such as of TNOs, and mid-IR observations of cold icy interstellar grains. Our new data can be used to identify and quantify $\mathrm{C}_{2} \mathrm{H}_{2}$ in ices, such as to estimate $\mathrm{C}_{2} \mathrm{H}_{2}$ column densities from absorption spectra. Detailed discussions are available for the application of band strengths to astronomical spectra and the determination of column densities (e.g., d'Hendecourt and Allamandola, 1986). To take a specific case, spectral details and optical constants for acetylene's $\nu_{5}$ band $\left(742 \mathrm{~cm}^{-1}, 13.48 \mu \mathrm{m}\right)$ are important since it is the strongest $\mathrm{C}_{2} \mathrm{H}_{2}$ feature within the $5-20 \mu \mathrm{m}$ observing range of the Spitzer-IRS instrument. Searches for IR spectral features of solid $\mathrm{C}_{2} \mathrm{H}_{2}$ in dense cold molecular clouds are in progress, and by applying our laboratory data, information on the column density, phase, and possibly temperature history, of $\mathrm{C}_{2} \mathrm{H}_{2}$ ices could be determined.

The study of trans-neptunian objects also will be aided by our new data, both through remote sensing and spacecraft fly-bys. In particular, the Ralph/LEISA instrument on the New Horizons mission will make hemispheric near-IR spectral observations at $1.25-2.5 \mu \mathrm{m}$ of Pluto and Charon at a resolution sufficient to map distributions of $\mathrm{N}_{2}, \mathrm{CO}, \mathrm{CH}_{4}$, and possibly other trace species, such as $\mathrm{C}_{2} \mathrm{H}_{6}$ and $\mathrm{C}_{2} \mathrm{H}_{2}$. As for TNOs other than Pluto, near-IR spectra of $\mathrm{CH}_{4}$ and $\mathrm{C}_{2} \mathrm{H}_{6}$ ices are consistent with the spectrum of Makemake, $2005 \mathrm{FY}_{9}$ (Brown et al., 2007) and possibly of Quaoar too (Schaller and Brown, 2007). Fig. 12 shows highresolution $\mathrm{H}$ - and $\mathrm{K}$-band spectra of Makemake (from Brown's Figs. 5 and 6), where the thick line is a smoothed version of the data, and where the blue continuum and $\mathrm{CH}_{4}$ ice have been subtracted (Brown, 2013, personal communication). ${ }^{2}$ Fig. 12 also shows our laboratory spectra for amorphous $\mathrm{C}_{2} \mathrm{H}_{2}, \mathrm{C}_{2} \mathrm{H}_{6}$, and

\footnotetext{
2 M. Brown has informed us that the modeling code used for the methane subtraction in our Fig. 12 differs slightly from that used in Brown et al. (2007).
} 

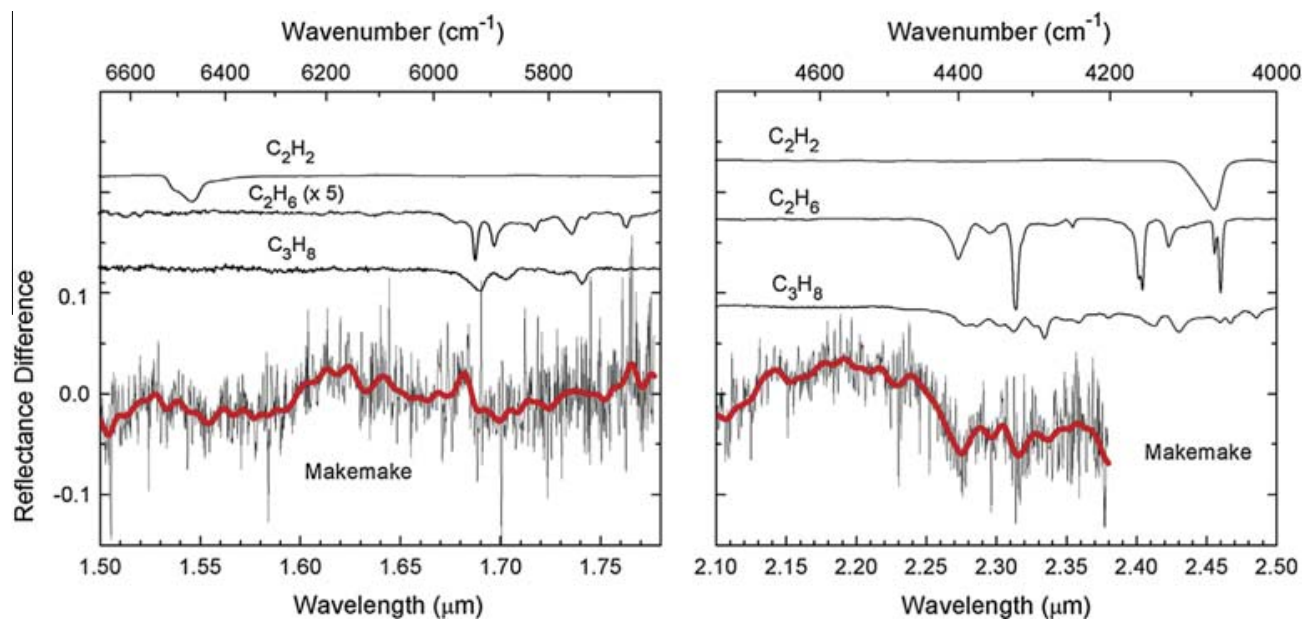

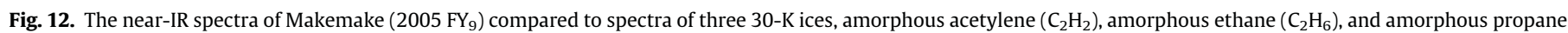
$\left(\mathrm{C}_{3} \mathrm{H}_{8}\right)$.

$\mathrm{C}_{3} \mathrm{H}_{8}$ (propane) at $30 \mathrm{~K}$ (Hudson et al., 2009 and unpublished work). As noted by Brown et al. (2007), their $100-\mu \mathrm{m} \mathrm{C}_{2} \mathrm{H}_{6}$ grain model agrees well with Makemake's spectrum beyond $2.25 \mu \mathrm{m}$ and between 1.68 and $1.78 \mu \mathrm{m}$. Since the observed spectrum around $1.55 \mu \mathrm{m}$ deviates from this same model (see Brown's Fig. 6), extra absorbers are suggested, and $\mathrm{C}_{2} \mathrm{H}_{2}$ is a candidate. In fact, acetylene is the only simple hydrocarbon that has a feature in this region. Makemake's spectrum also deviates from the ethane model beyond $2.32 \mu \mathrm{m}$, and Brown et al. (2007) have suggested $\mathrm{C}_{3} \mathrm{H}_{8}$ ice as a possible cause. Between 2.4 and $2.5 \mu \mathrm{m}, \mathrm{C}_{2} \mathrm{H}_{2}$, $\mathrm{C}_{2} \mathrm{H}_{6}$, and $\mathrm{C}_{3} \mathrm{H}_{8}$ ices all have distinctive IR features, but telluric absorptions make TNO observations extremely noisy in this region (e.g., Brown's Fig. 4). Of course for any quantitative spectral modeling, particle size and shape must be addressed and combined with spectra such as we show.

Future observations from telescopes, such as SOFIA and NGST, above the Earth's atmosphere may be needed to provide low-noise spectra. With such data we will have a better understanding of the contribution of $\mathrm{C}_{2} \mathrm{H}_{2}$ and other hydrocarbons to the chemical inventory of icy surfaces of outer Solar System objects.

\section{Conclusions}

Here we have measured and presented, for the first time, spectra of amorphous and crystalline $\mathrm{C}_{2} \mathrm{H}_{2}$ ice from 7000 to $500 \mathrm{~cm}^{-1}$ $(1.43-20 \mu \mathrm{m})$ at multiple temperatures in a single laboratory. From these data we have calculated the real $(n)$ and imaginary ( $k$ ) components of the complex index of refraction, from which measures of spectral intensity ( $A$ and $\alpha$ ) can be computed. All results are available on our web site ${ }^{1}$ along with a spreadsheet program to calculate spectra.

\section{Acknowledgments}

NASA funding through the Outer Planets Research and Cassini Data Analysis programs is acknowledged. MHM and RLH received partial support from the NASA Astrobiology Institute through the Goddard Center for Astrobiology. Michael Brown (California Institute of Technology) is thanked for providing the Makemake spectrum. We particularly thank Jim Moore who, over several years, developed nearly all of the MathCad computer routines used in this study. Perry Gerakines is acknowledged for programming favors with IDL.

\section{References}

Anderson, A., Andrews, B., Torrie, B.H., 1985. Raman and far infrared spectra of crystalline acetylene, $\mathrm{C}_{2} \mathrm{H}_{2}$ and $\mathrm{C}_{2} \mathrm{D}_{2}$. J. Raman Spectrosc. 16, 202-207.

Avram, M., Mateescu, G.D., 1972. Infrared Spectroscopy. Wiley Interscience, New York, pp. 112-114.

Bennett, C.J., Jamieson, C.S., Osamura, Y., Kaiser, R.I., 2006. Laboratory studies on the irradiation of methane in interstellar, cometary, and Solar System ices. Astrophys. J. 653, 792-811.

Bertie, J.E., Zhang, S.L., Keefe, C.D., 1994. Infrared intensities of liquids XVI. Accurate determination of molecular band intensities from infrared refractive index and dielectric constant spectra. J. Mol. Struct. 324, 157-176.

Bertie, J.E., Zhang, S.L., Keefe, C.D., 1995. Measurement and use of absolute infrared absorption intensities of neat liquids. Vib. Spectrosc. 8, 215-229.

Bottger, G.L., Eggers Jr., D.F., 1964. Infrared spectra of crystalline $\mathrm{C}_{2} \mathrm{H}_{2}, \mathrm{C}_{2} \mathrm{HD}$, and $\mathrm{C}_{2} \mathrm{D}_{2}$. J. Chem. Phys. 40, 2010-2017.

Boudin, N., Schutte, W.A., Greenberg, J.M., 1998. Constraints on the abundances of various molecules in interstellar ice: Laboratory studies and astrophysical implications. Astron. Astrophys. 331, 749-759.

Brown, R.H., Cruikshank, D.P., Tokunaga, A.T., Smith, R.G., Clark, R.N., 1988. Search for volatiles on icy satellites. I - Europa. Icarus 74, 262-271.

Brown, M.E. et al., 2007. Methane and ethane on the bright Kuiper Belt object 2005 FY9. Astrophys. J. 133, 284-289.

Carr, J.S., Najita, J.R., 2011. Organic molecules and water in the inner disks of T Tauri stars. Astrophys. J. 733, 102-120.

Cruikshank, D.P., Pilcher, C.B., Morrison, D., 1976. Pluto - Evidence for methane frost. Science 194, 835-837.

de Bergh, C., Schmitt, B., Moroz, L.V., Quirico, E., Cruikshank, D.P., 2008. Laboratory data on ices, refractory carbonaceous materials, and minerals relevant to transneptunian objects and centaurs. In: Barucci, M.A., Boehnhardt, H., Cruikshank, D.P., Morbidelli, A. (Eds.), The Solar System beyond Neptune. University of Arizona Press, Tucson, pp. 483-506.

DeMeo, F.E., de Dumas, C., Bergh, C., Protopapa, S., Cruikshank, D.P., Geballe, T.R., Alvarez-Caridal, A., Merlin, F., Barucci, M.A., 2010. A search for ethane on Pluto and Triton. Icarus 208, 412-424.

d'Hendecourt, L.B., Allamandola, L.J., 1986. Time dependent chemistry in dense molecular clouds. III - Infrared band cross sections of molecules in the solid state at $10 \mathrm{~K}$. Astron. Astrophys. Suppl. 64, 453-467.

Dows, D., 1966. Absolute infrared intensities in crystalline acetylene and ethane. Spectrochim. Acta 22, 1479-1481.

Edwards, D.F., Philipp, H.R., 1985. Cubic carbon (diamond). In: Palik, E.D. (Ed.), Handbook of Optical Constants of Solids, vol. 1. Academic Press, New York, pp. 665-673.

Engdahl, A., Nelander, B., 1983. The acetylene-water complex. A matrix isolation study. Chem. Phys. Lett. 100, 129-132.

Garland, C.W., Nibler, J.W., Shoemaker, D.P., 2003. Experiments in Physical Chemistry. McGraw Hill, New York, p. 53.

Groner, P., Stolkin, I., Günthard, H.H., 1973. Measurement of deposition rate in matrix spectroscopy with a small laser. J. Phys. E - Sci. Instrum. 6, 122-123.

Herman, M., Campargue, A., El Idrissi, M.I., Vander Auwera, J., 2003. Vibrational spectroscopic database on acetylene, $\mathrm{X}^{1} \Sigma \mathrm{g}^{+}\left({ }^{12} \mathrm{C}_{2} \mathrm{H}_{2},{ }^{12} \mathrm{C}_{2} \mathrm{D}_{2}\right.$, and $\left.{ }^{13} \mathrm{C}_{2} \mathrm{H}_{2}\right)$. J. Phys. Chem. Ref. Data 32, 921-1362.

Hollenberg, J.L., Dows, D.A., 1961. Measurement of absolute infrared absorption intensities in crystals. J. Chem. Phys. 34, 1061-1063.

Hudgins, D.M., Sandford, S.A., Allamandola, L.J., Tielens, A.G.G.M., 1993. Mid- and far-infrared spectroscopy of ices - Optical constants and integrated absorbances. Astrophys. J. Suppl. Ser. 86, 713-870. 
Hudson, R.L., Moore, M.H., Raines, L.L., 2009. Ethane ices in the outer Solar System: Spectroscopy and chemistry. Icarus 203, 677-680.

Johnson, R.E., 1989. Effect of irradiation on the surface of Pluto. Geophys. Res. Lett. $16,1233-1236$.

Keefe, C.D., Wilcox, T., Campbell, E., 2012. Measurement and application of absolute infrared intensities. J. Mol. Struct. 1009, 111-122.

Khanna, R.K., Ospina, M.J., Zhao, G., 1988. Infrared band extinctions and complex refractive indices of crystalline $\mathrm{C}_{2} \mathrm{H}_{2}$ and $\mathrm{C}_{4} \mathrm{H}_{2}$. Icarus 73, 527-535.

Knez, C., Moore, M.H., Ferrante, R.F., Hudson, R.L., 2012. Laboratory IR studies an astrophysical implications of $\mathrm{C}_{2} \mathrm{H}_{2}$-containing binary ices. Astrophys. J. 748, 95 104.

Levin, A., Meyer, C.F., 1928. The infrared absorption spectra of acetylene, ethylene, and ethane. J. Opt. Soc. Am. 16, 137-164.

Li, H.H., 1976. Refractive index of alkali halides and its wavelength and temperature derivatives. J. Phys. Chem. Ref. Data 5, 345-528, Note that the $\lambda^{4}$ term in equation (44) of $\mathrm{Li}(1976)$ should be $\lambda^{2}$. The same applies to the corresponding equation of Palik (1991).

Maeda, S., Schatz, P.N., 1961. Absolute infrared intensity measurements in thin films. J. Chem. Phys. 35, 1617-1621.

McMullan, R.K., Kvick, Å., Popelier, P., 1992. Structures of cubic and orthorhombic phases of acetylene by single-crystal neutron diffraction. Acta Cryst. B48, 726731.

Merlin, F., de Barucci, M.A., Bergh, C., DeMeo, F.E., Alverez-Candal, A., Dumas, C., Cruikshank, D.P., 2010. Chemical and physical properties of the variegated Pluto and Charon surfaces. Icarus 210, 930-943.

Moore, M.H., Ferrante, R.F., Moore, W.J., Hudson, R., 2010. Infrared spectra and optical constants of nitrile ices relevant to Titan's atmosphere. Astrophys. J. Suppl. Ser. 191, 96-112.

Mumma, M.J., Disanti, M.A., Dello Russo, N., Magee-Sauer, K., Gibb, E., Novak, R., 2003. Remote infrared observations of parent volatiles in comets: A window on the early Solar System. Adv. Space Res. 31, 2563-2575.

Nguyen, T.K., Viti, S., Williams, D.A., 2002. Molecular tracers of photo-evaporating disks around young stars. Astron. Astrophys. 387, 1083-1091.

Overend, J., 1982. The experimental determination of gas-phase infrared intensities. In: Person, W., Zerbi, G. (Eds.), Vibrational Intensities in Infrared and Raman Spectroscopy. Elsevier, Amsterdam, pp. 14-22.

Palik, E.D., 1991. Potassium bromide (KBr). In: Palik, E.D. (Ed.), Handbook of Optical Constants of Solids. Academic Press, New York, pp. 989-1004, See also the comment above for Li (1976).
Paul, S.O., Ford, T.A., 1989. Analysis of the infrared absorption spectra of solutions of water in some organic solvents. Part 2. Measurement of band intensities. J. Mol. Struct. 198, 65-75.

Plyler, E.K., Tidwell, E.D., Wiggins, T.A., 1963. Rotational-vibrational constants of acetylene. J. Opt. Soc. Am. 53, 589-593.

Quirico, E., Doute, S., Schmitt, B., de Bergh, C., Cruikshank, D.P., Owen, T.C., Geballe, T.R., Roush, T.L., 1999. Composition, physical state and distribution of ices at the surface of Triton. Icarus 139, 159-179.

Ramsay, D.A., 1952. Intensities and shapes of infrared absorption bands of substances in the liquid phase. J. Am. Chem. Soc. 74, 72-80.

Romanescu, C., Marschall, J., Kim, D., Khatiwada, A., Kalogerakis, K.S., 2010 Refractive index measurements of ammonia and hydrocarbon ices at 632.8 nm. Icarus 205, 695-701.

Sasaki, T., Kanno, A., Ishiguro, M., Kinoshita, D., Nakamura, R., 2005. Search for nonmethane hydrocarbons on Pluto. Astrophys. J. 618, L57-L60.

Schaller, E.L., Brown, M.E., 2007. Detection of methane on Kuiper Belt object (50000) Quaoar. Astrophys. J. 670, L49-L51.

Scrocco, M., Giuliani, R., Costarelli, C., 1972. Absolute integrated intensity measurements in solution hydrogen halides. Spectrochim. Acta 28A, 761 769.

Smith, W.H., 1969. Spectroscopic investigation of the structure of low temperature modification of the crystalline phase of acetylene and acetylene- $\mathrm{d}_{2}$. Chem. Phys. Lett. 3, 464-466.

Stäuber, P., Doty, S.D., van Dishoeck, E.F., Benz, A.O., 2005. X-ray chemistry in the envelopes around young stellar objects. Astron. Astrophys. 440, 949-966.

Swanepoel, R., 1983. Determination of the thickness and optical constants of amorphous silicon. J. Phys. E - Sci. Instrum. 16, 1214-1222.

Taylor, J.R., 1997. An Introduction to Error Analysis. University Science Books, Sausalito, California, pp. 45-79.

Tempelmeyer, K.E., Mills, D.W., 1968. Refractive index of carbon dioxide cryodeposit. J. Appl. Phys. 39, 2968-2969.

Thomas, B.H., Orville-Thomas, W.H., 1971. Infrared intensities of $v(C \equiv N)$ bands. J. Mol. Struct. 7, 123-135.

Wexler, A., 1967. Integrated intensities of absorption bands in infrared spectroscopy. Appl. Spectrosc. Rev. 1, 29-98.

Willacy, K., Woods, P.M., 2009. Deuterium chemistry in protoplanetary disks. II. The inner 30 AU. Astrophys. J. 703, 479-499.

Wilson, E.B., Wells, A.J., 1946. The experimental determination of the intensities of infrared absorption bands I. Theory of the method. J. Chem. Phys. 14, 578-580. 